\title{
EX-POST MERGER REVIEW AND DIVESTITURES
}

\author{
André Romahn \\ Richard Friberg
}


The Public-Private Sector Research Center is a Research Center based at IESE Business School. Its mission is to develop research that analyses the relationships between the private and public sectors primarily in the following areas: regulation and competition, innovation, regional economy and industrial politics and health economics.

Research results are disseminated through publications, conferences and colloquia. These activities are aimed to foster cooperation between the private sector and public administrations, as well as the exchange of ideas and initiatives.

The sponsors of the Public-Private Sector Research Center are the following:

- Ajuntament de Barcelona

- Departament d' Economia i Coneixement de la Generalitat de Catalunya

- Departament d' Empresa i Ocupació de la Generalitat de Catalunya

- Diputació de Barcelona

- Endesa

- Fundació AGBAR

- Institut Català de les Empreses Culturals (ICEC)

- Mediapro

- PricewaterhouseCoopers

- Sanofi

- ATM, FGC and TMB

The contents of this publication reflect the conclusions and findings of the individual authors, and not the opinions of the Center's sponsors. 


\title{
Ex-Post Merger Review and Divestitures*
}

\author{
Richard Friberg ${ }^{\dagger}$ \\ André Romahn $\ddagger$
}

December 10, 2012

\begin{abstract}
Divestitures have received little attention in ex-post evaluations of mergers. In partial remedy we simulate the effects of the Carlsberg-Pripps merger in the Swedish beer market and compare the predicted outcomes with those observed ex-post. There are no important price increases following the merger and prices of divested beers fell. Our merger simulations, that are based on a random coefficients logit model, capture these pricing patterns and suggest that the divestitures were important in limiting price increases. Knowledge of the retailer's markup rules allows us to discard retailer behavior as an explanation for the pricing patterns.
\end{abstract}

JEL Classification: K21, L11, L41, L66.

Keywords: Merger simulation, ex-post merger review, divestitures, demand for beer.

\section{Introduction}

Competition authorities frequently require that merging parties divest a number of brands or operations in order to clear a proposed merger (see for instance Motta (2004)). Are such divestitures important for the price effect of a merger? In this paper we take advantage of a rich data set to examine the effect of the divestiture of a number of brands to a small rival firm in the 2001 takeover of Swedish brewery Pripps by the Danish brewer Carlsberg. Carlsberg's pre-merger market share on the Swedish beer market was 33 percent and Pripps' was 16 percent. The prices of the divested beers fell by about 1 percent post-merger while prices of other beers increased by 2 percent. This points to a role for the divestitures in disciplining price increases. To more fully understand the role of divestitures we compare the merger as cleared with a counterfactual

${ }^{*}$ We are grateful to the Swedish Competition Authority, Handelsbankens Forskningsstiftelser and the Jacob Wallenberg foundation for financial support. Thanks to Anna Wikström (Systembolaget) and Lars Näsström (Research International) for providing the data. Valuable comments have been provided by Morten Olsen, Tobias Klein, Philip Schmidt-Dengler and Michael Waterson as well as seminar audiences at Paris School of Economics, the Swedish Competition Authority, IESE Business School, Uppsala University (national conference), and conference participants at the CRESSE 2012, IIOC 2012 and MACCI 2012. We are very grateful for receiving the Robert F. Lanzillotti prize for this paper at IIOC 2012.

${ }^{\dagger}$ Corresponding author: Stockholm School of Economics, PO Box 6501, SE-113 83, Stockholm, Sweden, phone: +46 8736 9602, e-mail: Richard.Friberg@hhs.se

${ }^{\ddagger}$ IESE Business School, Public-Private Sector Research Center, Avenida Pearson 21, 08034 Barcelona, Spain, phone: +34 93253 4200, e- mail: aromahn@iese.edu 
merger that allowed the merging parties to keep all brands.

We follow the seminal work of Berry, Levinsohn and Pakes (1995, BLP hereafter) and estimate a random coefficients logit model of demand that we use to generate counterfactual merger simulations. Our results suggest that the divestitures that were required by the Swedish competition authority to clear the merger were crucial in keeping price increases in check. If the merging parties were to control all the beers they controlled pre-merger, we predict that on average Carlsberg raises the prices of its products by about four percent, while the average price hike for the beers produced by Pripps is about nine percent. When averaging over all 262 beers in the market we predict an average price increase of about two percent. Employing a standard bootstrapping procedure to our simulation, we find that these price effects are significant at the 95 percent confidence level. In contrast, actual price developments following the merger were roughly flat; a finding well matched by our simulations of the merger as cleared.

Requirements on merging parties to change their structure (such as the set of brands controlled) or their behavior (such as length of contracts) take a central role in merger practice. These changes to the proposed mergers are typically referred to as 'remedies' while the term 'commitments' is also used in the European union. For instance, 56 percent of the proposed mergers that were subject to closer scrutiny by the European Competition Authority 1990-2011 were cleared subject to remedies (the Phase II procedure, no merger was blocked at previous stages). In comparison, only 13 percent were prohibited and 28 percent were permitted as proposed. Similarly, of 144 mergers challenged by US competition authorities between 2003 and 2007, 64 percent were allowed after remedies had been agreed upon (Tenn and Yun (2011)). ${ }^{1}$ In many jurisdictions, divestitures are the most prominent form of remedy. For example, 56 percent of the mergers cleared subject to remedies in the EU between 1996 and 2000 involved divestitures (DG Competition (2005)). Indeed, in the European Commission's notice on remedies it is stated that "Nevertheless, a general distinction can be made between divestitures, other structural remedies, such as granting access to key infrastructure or inputs on non-discriminatory terms, and commitments relating to the future behaviour of the merged entity. Divestiture commitments are the best way to eliminate competition concerns resulting from horizontal overlaps." (Commission (2008), paragraph 17, italics added).

Despite their importance in merger practice the literature that examines the role of divestitures in mergers is scant. Some, largely qualitative, descriptions of divestiture practice are found in for instance Elzinga (1962), Federal Trade Commission (1999) and DG Competition (2005). The latter two studies establish that in most cases the divested assets are still in operation a few years after the divestiture, and in this sense divestiture policy has been successful. These studies are silent on the developments of prices surrounding the mergers however and there are only a few detailed case studies of the price effects of divestitures.

A recent example is Tenn and Yun (2011) who provide a before-after analysis of the merger between J\&J and Pfizer and show that prices of divested brands fell post-divestiture. Pham

\footnotetext{
${ }^{1} 51$ percent were settled via consent orders and 13 percent were restructured after the Department of Justice communicated its concerns to the merging firms.
} 
and Prentice (2010) examine a merger in the Australian cigarette industry that involved divestitures and compare results to counterfactual simulations based on a nested logit model of demand. Data limitations force them to estimate demand for a period several years before the actual merger, but their results nevertheless suggest that divestitures lowered price increases. Also the theoretical work on divestitures is limited. One theme that has been developed is that divestitures may facilitate collusion if they lead to a more symmetric industry structure (see for instance Compte, Jenny and Rey (2002)). Cosnita and Tropeano (2009) examine how a competition authority can use policies regarding divestitures to induce the merging parties to reveal private information on the efficiency gains of the merger. Vasconselos (2010) uses a stylized setting with four, ex-ante symmetric, Cournot competitors to show that divestitures can increase consumer surplus by creating a more efficient competitor.

Our paper also aims to contribute to the growing literature that provides ex-post evaluations of mergers; see for instance Focarelli and Panetta (2003), Hastings (2004), Taylor and Hosken (2007) and Ashenfelter and Hosken (2011)). ${ }^{2}$ A typical finding is that there are modest price increases of a few percent associated with the merger. In a related line of research, a few papers have compared the predicted price changes from merger simulations with the actual development of prices after the merger where the results of Björnerstedt and Verboven's (2012) study of a merger on the Swedish market for painkillers are particularly encouraging. Peters (2006) and Weinberg (2011) are other examples that compare predictions from merger simulations to ex-post developments of prices. These latter papers point to difficulties in accurately predicting effects if one uses demand models that place strong restrictions on substitution patterns between products.

To avoid this concern we estimate demand using a random coefficient logit model, which has become the method of choice in published work (see for instance BLP (1995), Nevo (2000a) or Petrin (2002)). ${ }^{3}$ We believe that the evidence in this paper stresses the role of merger simulations in guiding what divestitures competition authorities should pursue. The implicit focus in much discussion of the pros and cons of merger simulations is that they should be used to determine which mergers to block and which to allow (see for instance Angrist and Pischke (2010) and Einav and Levin (2010)). It has also been noted that even carefully executed merger simulations are difficult to bring into the court room. We suggest that the greatest value for merger simulations may lie in the ability to evaluate different divestitures and different buyers. For such purposes merger simulation can form the basis for a discussion with the merging parties

\footnotetext{
${ }^{2}$ Many researchers have called for such reviews (for instance Whinston (2006)). In their critical view of Industrial Organization, Angrist and Pischke (2010, p. 20) highlight the lack of ex-post merger reviews. "An important question at the center of the applied industrial organization agenda is the effect of corporate mergers on prices. One might think, therefore, that studies of the causal effects of mergers on prices would form the core of a vast micro-empirical literature, the way hundreds of studies in labor economics ... But it isn't so. In a recent review, Ashenfelter, Hosken, and Weinberg (2009) found only about 20 empirical studies evaluating the price effects of consummated mergers directly." In the same issue of the Journal of Economic Perspectives Einav and Levin (2010) point to the idiosyncracies of mergers and the limits of what can be learnt from ex-post reviews, see also Carlton (2009).

${ }^{3}$ On a related note, even richer models examine mergers without assuming, as we do, static forms of competition (see for instance Benkard, Bodoh-Creed and Lazarev (2010)).
} 
and explaining the intricacies of demand estimation to lawyers is less of an issue.

Our case study also suggests weaknesses of limiting the analysis to mechanically calculated changes in concentration measures when evaluating mergers in differentiated product markets. In our data the price of divested beers fell despite an increase in the concentration in the market. In an analysis that is explicitly based on the set of cross-price effects that firms consider when setting prices the possibility of such a result is intuitive - the more products a firm controls, and the closer these products are as substitutes, the higher are prices. Stripping away a set of products and giving control of these divested products to a small firm can generate a fall in prices as a different set of cross-price effects determines equilibrium prices. In counterfactual simulations we show that giving control of the divested beers to the second largest player after the merger, Spendrups, would have substantially limited the price decrease of divested beers. The estimated substitution patterns are important in driving our results, which points to the potential value of using demand models that allow for rich substitution patterns in merger analysis. In contrast to logit and nested logit models, the random coefficients logit model allows observable product characteristics to determine substitution patterns. This raises the realism of our merger simulation.

Several features of our data, and of the institutional setting, make the Pripps-Carlsberg merger an appealing case for examining the role of divestitures, also for those that do not have a particularly strong interest in the Swedish beer market per se. We use package-level data on prices and quantities for the whole market, rather than an estimate based on a selection of stores, as is frequently the case with scanner data. The data source is the Swedish government-owned retailer, Systembolaget. An additional benefit of the institutional setting is that Systembolaget applies the same transparent markup to all products. With knowledge of the retailer's pricing rule, we can directly back out the producer price that the profit maximizing brewers and importers charge to Systembolaget and do not have to address the strategic interaction between wholesalers and retailers as in Villas-Boas (2007). This increases accuracy.

We were also attracted by the beer market having been a prominent testing ground for merger simulations right from the start of this literature; see Baker and Bresnahan (1985), Hausman et al. (1994) for examinations of prospective mergers on the US beer market and Pinkse and Slade (2004) for mergers on the UK beer market. ${ }^{4}$

The paper is structured as follows. Section 2 describes the data, institutional setting and developments surrounding the Carlsberg-Pripps merger. Section 3 presents the model used to estimate the demand side, while section 4 addresses the supply side. In the subsequent section, we detail our estimation procedure and the results. In Section 6 we conduct our (counterfactual) merger simulations. To provide understanding for the effects, we adapt the concept of upward pricing pressure (UPP, Farrell and Shapiro (2010)) to a stylized merger with and without a divested product. In this setting setting, it is straightforward to show that divestitures can yield falling prices post-merger. Section 7 concludes.

\footnotetext{
${ }^{4}$ See also Hellerstein (2008) or Rojas (2008) who examine the beer market with similar tools as the merger simulation literature, but focus on the pass-through of exchange rates and of excise taxes, respectively.
} 


\section{Data and Institutional Setting}

Our data set includes the monthly nationwide retail sales of all beers with a minimum alcoholic content of 3.5 percent by volume and has been provided to us by the Swedish retail monopoly for alcohol, Systembolaget. The data covers the period from January 1996 to June 2001. The merger between Carlsberg and Pripps was officially cleared by the Swedish competition authority in December 2000 and consummated in February 2001. To estimate our demand model, we use the sales data up to and including November 2000, the month prior to the official clearing of the merger. To compare the simulated price effects with the actual ones, we use the time period from February 2001 to June 2001. Thus, our merger simulation is ex-ante and we compare its predictions to the actual ex-post outcomes.

Sales volume per month and price per liter measured in Swedish krona (SEK) are observed at the barcode level and we use the terms beer, product and variety interchangeably. ${ }^{5}$ Samuel Adams Boston Lager in a 33 centiliter $(\mathrm{cl})$ bottle is an example of a beer. We use the term umbrella brand to denote the case where a number of beers with different characteristics are sold under the same name; Budweiser, Guinness and Warsteiner are examples of umbrella brands.

Apart from prices and liters sold, Systembolaget provides more useful information about the beers it has on offer in its catalogs. These catalogs are freely available online or in the retail outlets of the monopoly, so that consumers have easy access to them. Systembolaget classifies beers into different categories and we use beers in the ale, dark lager, light lager, stout and wheat beer segments of the market. We exclude special and spontaneously fermented beers. ${ }^{6}$ Moreover, we also exclude beers that are not sold in one of the standard sizes: bottles and cans of around $33 \mathrm{cl}$ or $50 \mathrm{cl}^{7}$

As further product characteristics, Systembolaget provides consumers with taste information. It attributes to each beer values for richness, sweetness and bitterness, which are all measured on a scale from one to twelve, where higher values indicate 'more' taste. The alcohol content of a beer also affects its taste and we therefore include it as an observable product characteristic. We also include a measure of advertising expenditure. ${ }^{8}$ During the period of study advertising of alcoholic beverages was illegal in Sweden. An exemption was made for beer with an alcoholic content below 2.25 percent of volume. These kinds of beers could be freely sold in supermarkets. In cases where such a low alcohol beer has the same brand name as a beer sold in the outlets of the retail monopoly, we use the advertising expenditure on the low alcoholic version as a measure for the advertising of the stronger beer. At the level of umbrella brands, there are 32

\footnotetext{
${ }^{5}$ In November 2000, 8.62 SEK equalled one Euro and 10.08 SEK equalled one US dollar. Thus, the average price for a liter of beer was roughly 4 Euro and 3.4 US dollar, respectively.

${ }^{6} \mathrm{An}$ example of a special beer is a product that is branded by a Swedish football club and therefore targets exclusively fans of that particular club. Belgian beers with various fruit tastes also fall into this category. Both the special and spontaneously fermented beer segments are negligible in terms of sales volumes and can therefore be safely disregarded in the merger analysis.

${ }^{7}$ Thus, cans of $45 \mathrm{cl}$ and $60 \mathrm{cl}$ are included, but kegs of 3 liters are excluded in the demand estimation. Non-standard package sizes account for a miniscule share of sales volume.

${ }^{8}$ Source: Research International/SIFO. Advertising expenditure is the estimate of the total cost of advertising for a given beer in magazines, newspapers, television and billboards based on the observed advertising.
} 
brands for which we observe positive advertising expenditure. This represents less than eight percent of all umbrella brands in the sample. Across our demand specifications below, we find that this form of advertising raises product sales.

Further, we include dummies for the different packaging and beer categories as well as a dummy depicting if a beer is produced or imported by a non-Swedish firm. Table 1 lists all of the observable product characteristics with their means and standard deviations. In case of the dummies, the means simply report the fraction of beers falling into a specific category.

The price for a given beer is the same across all of Sweden and prices can change only when there is a new catalog issued by Systembolaget. Ackerberg and Rysman (2005) stress that including periods without any changes in prices or the number of products does not aid in the identification of the parameters determining consumer demand. We take this into account and drop all the periods in-between issues of Systembolaget catalogs. Estimating a standard logit model on the data with and without these periods yields almost identical demand parameters. Therefore, these periods indeed do not seem to contain relevant additional variation to identify our parameters of interest.

There are no temporary sales and the prices that consumers pay are determined by a deterministic markup on the price set by producers or importers. The ingredients in this markup on the producer price are the following: an excise tax on alcohol that is calculated per liter, a percentage markup applied by Systembolaget that is common to all products, value added tax (VAT) of 25 percent and, in the case of some beers, a deposit on the container. There have been a handful of changes to these variables as well as in how the markup is calculated over the period of study, in Section 4 we describe the calculation of the markup in detail. The percentage markup that Systembolaget adds is determined by Swedish parliament and is changed once during the period covered by the data, namely in January 2000. We use the information on these building blocks of the markup to back out the time series of producer prices and product-level marginal costs. Finally, to compute market shares, we have to delineate the potential market size. We have also been provided with the total number of liters of wine sold in the outlets of the retail monopoly. As wine can be seen as a relatively close substitute to beer, we define the potential market as the sum of the total liters of wine and beer sold. Compared with defining the potential market as a fixed consumption of say five liters of beer per capita per month, this has the advantage that wine and beer sales exhibit very similar seasonal sales cycles (see Figure 1). Both markets spike during the summer months and around Christmas. We therefore avoid substitution away from the outside good during peak demand seasons. Similarly, we avoid substitution towards the outside good in-between peak demands.

\subsection{The Swedish Beer Market}

We turn to a more detailed description of the Swedish beer market and the merger between Carlsberg and Pripps. A useful way to describe the suppliers to Systembolaget is as follows: major brewers, microbreweries and pure importers. 
The major brewers are Åbro, Carlsberg, Krönleins, Pripps, and Spendrups. Pripps was at the time of the merger owned by Norwegian food and drinks group Orkla. Krönleins and Spendrups are family controlled domestic brewers and Åbro is an independent Swedish brewer. Each of these brewers produces, and sells to Systembolaget, a number of 'their own' beers. They also produce some beers on license agreements with foreign brewers and act as importers and wholesalers for other beers. At the start of the period Carlsberg for instance was the wholesaler for imported beers under the umbrella brands of Budweiser, Caffrey's, Michelob and Staropramen. Micro breweries and independent importers make up a small share of overall volume but control a large number of beers.

In Table 2 we present statistics on prices and quantities, as well as concentration measures for the market as a whole and a selection of brewers. Figure 1 shows that over our sample period, beer sales have trended upwards. Using the plotted linear trend, monthly liters of beer sold have increased by 74 percent over the sample period from 6.5 to 11.4 million liters. The liters of wine sold are plotted as the dashed line. It is evident that the two segments indeed exhibit very similar sales cycles.

Turning to the firm-level, Carlsberg, Pripps and Spendrups control roughly a quarter of the market each in the first years of the study. Åbro is the fourth largest supplier with a market share that is rather stable around ten percent. Summing these firms' market shares for each period gives a four-firm concentration ratio between 72 and 87 percent over our sample period. The Herfindahl-Hirschman index fluctuates around .2 before the merger, and jumps above .27 following the merger between Carlsberg and Pripps.

According to the U.S. Department of Justice Merger Guidelines, the Carlsberg-Pripps merger therefore changed the Swedish beer market from a moderately to a highly concentrated industry.

\subsubsection{The Carlsberg-Pripps Merger}

The takeover of Pripps by Carlsberg had an international dimension and was investigated by competition authorities in Denmark, Finland, Norway and Sweden. Carlsberg merged with Norwegian brewery Ringnes, which owned Pripps and in turn was owned by Norwegian food and drinks group Orkla. A joint entity was created under the name Carlsberg breweries where Orkla received a 40 percent share. According to reports at the time of the merger, an important motivation was that Carlsberg wanted access to Baltic Beverages Holding Co., that had a strong position in the Russian beer market, and that was owned to 50 percent by Ringnes. Carlsberg and Pripps also sold beer with alcohol content below 3.5 percent that were retailed in supermarkets, bottled water and carbonated soft drinks. By focusing on the market for beer with alcohol content above 3.5 percent in Sweden we thus examine only part of the merger. The part that we examine was viewed as a separate relevant market in the product and the geographic space by the competition authorities.

During the fall of 2000, the merger is investigated by the Swedish competition authorities and, following a number of divestitures, the Swedish competition authority announces that it will not 
challenge the merger in December 2000. The merger is finally consummated in February 2001. We use February as the start of the ex-post period to evaluate the pricing impact of the merger. The solid vertical lines in Figures 1 and 2 indicate January 2001 - in between the clearing of the merger and its official consummation.

The terms of the merger stipulate that seven domestic and five imported umbrella brands, should be divested. ${ }^{9}$ The divested brands were transferred to Galatea, an independent wholesaler with no production capacity of its own. Galatea thereby expanded from a market share of less than half a percent to one of more than six percent following the merger.

\subsubsection{The Behavior of Prices Before and After the Merger}

The potential for substantial price effects of the merger is evidenced by the combined pre-merger market share of Carlsberg and Pripps of about 50 percent and the increased concentration in the industry following the merger. Figure 2 presents the quantity weighted price for the market as a whole, the two product portfolios of the merging parties and the beers that were required to be divested for the merger to be cleared by the Swedish competition authority. To make the comparison of price trends before and after the merger, we strip out the divestitures from the holdings of Carlsberg and Pripps before the merger. For the same reason, we also keep the price series of Pripps and Carlsberg separate in the post-merger period, even though they are a joint entity in this period.

Post-merger, we can observe two facts. First, the prices of Carlsberg's and Pripps' products as well as the overall market price for beer tend upwards. Second, the divested products behave in the opposite way. Their prices tend to fall post-merger. Overall, however, the merger's effect on prices is small. We define the pre-merger window to include the months from January 2000 up to November 2000 and a post-merger window to cover February 2001 to June 2001. Comparing prices at the end of the post-merger period, June 2001, with those at the end of the pre-merger period, November 2000, we find the following patterns. The prices of Carlsberg's products rise by about 2.3 percent, while Pripps' prices increase by about 1.9 percent. The divestitures on the other hand lower their prices by 1 percent, while the average price increase for the overall market is 2 percent.

As an alternative, we compare the prices at the end of the pre-merger period with those in March 2001, the month immediately after the consummation of the merger on February 15, 2001. For this case, the prices of Carlsberg's and Pripps' beers rise by 1.8 and 1.9 percent, respectively, while the price hike for the overall market is 1.4 percent. The divestitures lower prices by about half a percent. Galatea's products see price increases of about 1.7 percent. This finding is still valid for April, but in the following two months Galatea lowers the prices of the products it owned before the Carlsberg-Pripps merger. We think this change in prices is unrelated to the

\footnotetext{
${ }^{9}$ The domestic brands that were divested were Arboga, Bayerbräu, Eagle, Fat, Sailor, Starkbock and TT. The imported brands that were divested were Bass, Caffrey's, Lapin Kulta, Staropramen and Warsteiner. All brands except Lapin Kulta were divested to Galatea. Lapin Kulta was sold to Åbro in 2002, and is therefore treated as controlled by the merging parties in this paper.
} 
merger and the acquisition of the divested beers by Galatea.

Table 3 complements this evidence on the different pricing patterns by computing the correlation patterns between prices for our chosen pre- and post-merger windows. Before the merger, the price of the divested products is roughly uncorrelated with the prices of the market overall and the prices of the product portfolios of Carlsberg and Pripps. Post-merger, however, we observe an almost perfect negative correlation between the price of the divested beers on the one hand and the prices of the overall market and Carlsberg's product portfolio on the other.

\section{Modeling Demand}

Adopting a structural approach to modeling demand allows us to simulate the effects of the merger between Carlsberg and Pripps on market outcomes before the merger actually takes place. We use data up to and including November 2000, the month prior to the official clearing of the merger, to simulate the post-merger outcomes for different cases. Our focus lies on the role of the brands that were required to be divested by the Swedish competition authority. As in the merger simulation in Nevo (2000b), we follow the seminal work of BLP (1995), and estimate a random coefficients logit model of product demand. The BLP framework allows for very flexible patterns of substitutability between different beers. Compared with the standard logit model, product characteristics can influence the estimated cross-price elasticities, instead of pinning down all the elasticities with observed market shares only. This yields more realistic substitution patterns and product-level marginal cost estimates, which in turn raises the accuracy of the merger simulation.

\subsection{The Random Coefficients Logit Model}

We briefly present the demand model. Readers interested in a more complete description of the random coefficients logit model can refer to the exposition in Nevo (2000b).

We observe $t=1, \ldots, T$ periods with a total number of $J_{t}$ beers in each. The indirect utility of consumer $i$ from purchasing beer $j$ at date $t$ is given by

$$
u_{i j t}=\delta_{j t}+\mu_{i j t}+\epsilon_{i j t}, i=1, \ldots, I, j=1, \ldots, J_{t}, t=1, \ldots, T \text {. }
$$

$\delta_{j t}$ is variety $j$ 's mean utility, which is identical across consumers. $\mu_{i j t}$ is consumer $i$ 's specific deviation from the product-specific mean utility.

$$
\delta_{j t}=x_{j t} \beta-\alpha p_{j t}+\xi_{j t}
$$

$x_{j t}$ is a $K_{1}$-dimensional row-vector containing the observable product characteristics of beer $j$. These characteristics are listed in Table 1. Richness, sweetness and bitterness are taste 
attributes that are measured on a scale from 1 to 12 with higher values indicating 'more' taste. The alcohol content of each beer is included as well, along with a measure of the advertising expenditure for the beer brand and dummies for the different types of packaging. We also allow for beer-type specific effects by including a dummy differentiating between domestic and foreign beer varieties, as well as ale, dark lager, stout and wheat beer dummies. The popular light lager segment is the base category. Apart from including a constant, we also allow for a linear time trend.

$\xi_{j t}$ captures all product-specific attributes that are unobserved by the econometrician, but known to beer producers and consumers. These can be viewed simply as i.i.d. demand shocks and when simulating merger outcomes, we hold these estimated shocks constant for each product. This is a standard assumption in the literature (see for instance Nevo 2000a, Berry and Pakes (2001)).

$$
\mu_{i j t}=\widetilde{x}_{j t} \Sigma v_{i}, v_{i k} \sim N(0,1), k=1, \ldots, K_{2}
$$

$\mu_{i j t}$ allows for heterogeneity in consumer tastes. We select a subset, $\widetilde{x}_{j t}$, of the observable product characteristics for which we allow random coefficients. $\widetilde{x}_{j t}$ is a $K_{2}$-dimensional row vector and includes price, sweetness, alcohol content and a constant. $\Sigma$ is a $K_{2}$ dimensional square matrix with $\sigma$ on its diagonal and all off-diagonal elements are equal to zero.

We do not observe the purchases of a panel of consumers directly, but only aggregated sales for each of the products. Therefore, for each period $t, I=100$ different types of consumers are simulated and each of these consumer types is fully described by the $K_{2}$-dimensional column vector $v_{i}$.

Each entry in this vector is a realization from a standard normal distribution that measures how much a specific consumer values one of the $K_{2}$ characteristics and price. A positive (negative) draw for $v_{i 1}$ indicates that consumer $i$ is more (less) price sensitive than the average consumer. Similarly, a positive draw for $v_{i 3}$ implies that consumer $i$ values the alcohol content of a beer more than the average consumer.

$\sigma$ is the $K_{2}$-dimensional column vector of containing the standard deviations of the random coefficients. Without heterogeneity among consumers each entry of $\sigma$ is zero. In this case, consumers' indirect utility is completely determined by the mean utility term, $\delta$, and the logitdistributed taste shock, $\epsilon$, and therefore the standard logit model is correctly specified. If $\sigma \neq 0$, the standard logit model is mis-specified. To better illustrate the resulting distributions of the estimated random coefficients, we rewrite (1) as follows.

$$
u_{i j t}=x_{j t} \beta_{i}-\alpha_{i} p_{j t}+\xi_{j t}+\epsilon_{i j t}
$$

The price and taste coefficients vary among consumers with the following distributions.

$$
\begin{aligned}
\alpha_{i} & \sim N\left(\alpha, \sigma_{1}\right) \\
\beta_{i k} & \sim N\left(\beta_{k}, \sigma_{k}\right), \quad k=2, \ldots, K_{2}
\end{aligned}
$$


Imposing the logit assumption on the taste shocks $\epsilon_{i j t}$ and integrating, yields the probability that simulated consumer $i$ purchases beer $j, s_{i j t} .{ }^{10}$ The market share of product $j$ is the average of the consumer-specific purchase probabilities.

$$
s_{j t}=I^{-1} \sum_{i=1}^{I} s_{i j t}=I^{-1} \sum_{i=1}^{I} \frac{\exp \left(\delta_{j t}+\mu_{i j t}\right)}{1+\sum_{k=1}^{J_{t}} \exp \left(\delta_{k t}+\mu_{i k t}\right)}
$$

Here, we have normalized the utility of the outside option, namely not buying beer, to zero, $\delta_{o t}+\mu_{i o t}=0, \forall i, t$. The own- and cross-price elasticities for each particular beer $j$ are computed analogously.

$$
\eta_{j k t}= \begin{cases}\frac{p_{j t}}{s_{j t}} I^{-1} \sum_{i=1}^{I}-\alpha_{i} s_{i j t}\left(1-s_{i j t}\right) & , j=k \\ \frac{p_{j t}}{s_{j t}} I^{-1} \sum_{i=1}^{I} \alpha_{i} s_{i j t} s_{i k t} & , j \neq k\end{cases}
$$

Looking at the expression for the cross-price elasticity between a beer $j$ and its rival $k$, it is clear that beers with similar choice probabilities for each of the $I$ consumers are more substitutable than beers that differ substantially in the individual choice probabilities. $s_{i j t}$ and $s_{i k t}$ will be close to each other, if the two beer varieties have similar characteristics. Then, both the two products' mean utilities and their individual-specific deviations from mean utility are of similar size.

In short, in the BLP model, beers with similar characteristics tend to be more substitutable than beers with very different product attributes. This raises the credibility and realism of the estimated substitution patterns compared with the standard logit model.

In the standard logit model, products with similar aggregate market shares are more substitutable than products with very different market shares. This holds irrespective of the two beers' characteristics. With at least 213 varieties of beers available at each date, the logit model is bound to estimate several beers with very different characteristics to be highly substitutable.

\section{Modeling Supply}

To model the supply side of the Swedish beer market, we impose Nash-Bertrand competition between firms. The relevant firms here are the producers/wholesalers that act as suppliers to the government retail monopoly. There are $f=1, \ldots, F_{t}$ firms present at date $t$ and each firm maximizes profits for its portfolio of products, $\mathcal{F}_{f}$.

$$
\max _{p_{j t}^{w}} \Pi_{f}=\sum_{j \in \mathcal{F}_{f}} M_{t} s_{j t}\left(p_{j t}^{r}\right)\left(p_{j t}^{w}-m c_{j t}\right)-C_{f}
$$

$p_{j t}^{r}$ and $p_{j t}^{w}$ are the retail and wholesale prices. $M_{t}$ is the market size at date $t, m c_{j t}$ is the marginal cost of production for beer $j$ and $C_{f}$ is the fixed cost faced by firm $f$. We distinguish

\footnotetext{
${ }^{10} \epsilon_{i j t}$ is i.i.d. and has a Type I extreme value distribution.
} 
between retail and wholesale prices, because product shares and elasticities are functions of the prices charged to consumers, while firm margins directly depend on the prices charged to the retail monopoly. An attractive feature of the Swedish beer market is the deterministic relationship between retail and wholesale prices. The retail monopoly applies a fixed formula when determining retail prices. ${ }^{11}$

$$
p_{j t}^{r}=\left(p_{j t}^{w}+x_{j t}^{a} \tau_{t}^{a}\right)\left(1+\tau_{t}^{c}\right)\left(1+m k_{t}^{s}\right)+d_{j t}
$$

$x_{j t}^{a}$ is the per liter alcohol content of beer $j, \tau^{a}$ and $\tau^{c}$ are the alcohol excise tax and VAT, while $m k^{s}$ and $d_{j t}$ are the markup of the retail monopoly and the deposit for the packaging of product $j$, respectively. As emphasized by the indexing, the tax rates and the retail markup are equal for all products. When setting wholesale prices, firms therefore have certainty about the final price charged to consumers.

Knowledge of (9) allows us to precisely back out firm margins, $p_{j t}^{w}-m c_{j t}$. We define $\kappa_{t} \equiv$ $\partial p_{j t}^{r} / \partial p_{j t}^{w}=\left(1+\tau_{t}^{c}\right)\left(1+m k_{t}^{s}\right)$. The first-order profit maximization condition for product $j \in \mathcal{F}_{f}$ is given by

$$
\sum_{k \in \mathcal{F}_{f}} \frac{\partial s_{j t}}{\partial p_{k t}^{r}}\left(p_{k t}^{w}-m c_{k t}\right)=-\frac{s_{j t}}{\kappa_{t}}
$$

Switching to matrix notation, we collect the profit maximization conditions for all firms in the market and define the entry in the $j$ th row and $k$ th column of the matrix of market share derivatives, $\Omega$, as follows.

$$
\begin{gathered}
\Omega(j, k) \equiv \begin{cases}\frac{\partial s_{k t}}{\partial p_{j t}^{r}} & , \exists\{j, k\} \subset \mathcal{F}_{f} \\
0 & , \text { otherwise }\end{cases} \\
\Omega_{t}\left(p_{t}^{w}-m c_{t}\right)=-s\left(p_{t}^{r}\right) \kappa_{t}^{-1}, \forall t
\end{gathered}
$$

$\Omega_{t}$ takes into account the actual ownership pattern of beers at date $t$. We thereby impose a Nash-Bertrand equilibrium, where firms are the players. To illustrate, setting all off-diagonal elements of $\Omega_{t}$ to zero, defines the products as the relevant players and models firms as ignoring the cross-price elasticities between the individual beers in their holdings.

By inverting $\Omega_{t}$, we can now solve explicitly for firms' price-cost margins, given the assumption of Nash-Bertrand competition.

$$
p_{t}^{w}-m c_{t}=-\Omega_{t}^{-1} s\left(p_{t}^{r}\right) \kappa_{t}^{-1}
$$

\footnotetext{
${ }^{11}$ The formula changes in December 1999. Before this it is given by $p_{j t}^{r}=\left(p_{j t}^{w}+x_{j t}^{a} \tau_{t}^{a}\right)\left(1+m k_{t}^{s}\right)\left(1+\tau_{t}^{c}\right)+d_{j t}$. From January 2000 onwards, the retail price is $p_{j t}^{r}=\left(p_{j t}^{w}\left(1+m k_{t}^{s}\right)+c_{t}+x_{j t}^{a} \tau_{t}^{a}\right)\left(1+\tau_{t}^{c}\right)+d_{j t}$, where $c_{t}$ is a constant, per container, charge applied to all beers. From January $2000 c_{t}$ is 1.5 SEK. For backing out the marginal costs implied by our demand estimates, we are interested in $\partial p_{j t}^{r} / \partial p_{j t}^{w}$. It is straightforward to verify that this equals $\left(1+\tau_{t}^{c}\right)\left(1+m k_{t}^{s}\right)$ for all the pricing functions.
} 
Wholesale prices, market shares and $\kappa_{t}$ are observed directly, while the elements of $\Omega_{t}$ are functions of the estimated demand parameters. Marginal costs can be backed out by rearranging and plugging in the estimated parameters.

\section{Estimating Demand}

Our estimation algorithm follows the nested fixed point approach (NFP), which goes back to BLP and has been popularized by the detailed guide provided in Nevo (2000a). The NFP algorithm consists of an outer and an inner loop. In the outer loop, an optimization algorithm determines the minimum of the GMM estimator's objective function.

$$
Q(\xi(\sigma))=\min _{\sigma}\left(\xi(\sigma)^{\prime} Z\right) W\left(Z^{\prime} \xi(\sigma)\right)
$$

$W$ is the weighting matrix and $Z$ is the matrix of instrumental variables. It is possible to express the GMM objective function only in terms of the standard deviations of the random coefficients, $\sigma$, because the means of the random coefficients are a function of $\sigma$ (Nevo (2000b)). For each candidate value of $\sigma$, the inner loop solves for the mean utilities, $\delta$, that equate observed market shares, $S$, with those implied by the model, $s(\delta ; \sigma)$, by iterating over the following contraction mapping.

$$
\delta_{t}^{h+1}=\delta_{t}^{h}+\ln \left(S_{t}\right)-\ln \left(s_{t}\left(\delta_{t}^{h} ; \sigma\right)\right), \quad t=1, \ldots, T, h=0, \ldots, H
$$

$H$ is the number of iterations needed to attain convergence of successive iterates within the chosen tolerance level of the inner loop, $\epsilon_{t o l}$.

$$
\left\|\delta_{t}^{h+1}-\delta_{t}^{h}\right\| \leq \epsilon_{t o l}
$$

Dubé et al. (2012) and Knittel and Metaxoglou (2012) demonstrate potential pitfalls in the NFP approach. We take lessons from both papers in the setup of our estimation algorithm. Dubé et al. (2012) show that a loose tolerance for the inner loop can cause the optimization in the outer loop to fail to converge or to converge at a point that is not a local minimum. We address this issue by setting a tight tolerance level, $\epsilon_{t o l}=1 e-14$.

Knittel and Metaxoglou (2012) emphasize that different optimization algorithms can converge at different candidate minima. The same holds for different initial guesses for $\sigma$ for any given optimization routine. We therefore use 100 randomly generated starting values for $\sigma$ and employ a quasi-Newton and a simplex optimization method to pin down the candidate minima. We provide the quasi-Newton method with an analytical gradient. The weighting matrix is updated and the process is repeated to arrive at a second set of candidate minima. We adopt the minimum of these values as the global minimum and base all our computations on these values for $\sigma$. 
The alternative to the NFP approach is to cast the estimation as a mathematical program with equilibrium constraints (MPEC, Dubé et al. (2012), Su and Judd (2012)). MPEC replaces the need for an inner loop with equilibrium constraints and thereby typically yields substantial speedups in the estimation and eliminates a potential source of numerical error. The size of the speedup is greatest for data with relatively many markets and relatively few products. As we only observe 31 markets with between 213 and 293 products, we are somewhat skeptical regarding the expected speedup for our specific application. Moreover, our tight convergence criterion for the inner loop should ensure that the outer loop pins down valid candidate minima of the GMM objective function. We therefore stick to the NFP approach for our data at hand.

\subsection{Instruments}

We next address the issue of endogenous prices. The unobservable product characteristic $\xi$ has a vertical interpretation in the model. All else equal, a higher realization of $\xi_{j t}$ gives product $j$ a greater market share. In other words, consumers' willingness to pay is increasing in the unobservable product characteristic. As firms incorporate this into their pricing decisions, realizations of the unobservable and price will tend to be positively correlated, which in turn renders prices endogenous and biases the estimated price coefficient towards zero.

This is a well-known problem in the existing literature and we follow the instrumenting strategies of BLP and Bresnahan et al. (1997). These instruments rely on the assumption that each product's location in characteristics space is exogenous. The optimal price of each product depends on its own attributes as well as the attributes of all other rival products. Given exogeneity, any function of the observed non-price characteristics qualifies as an instrument for price. We therefore instrument for the price of each product with its own characteristics, the sum of the characteristics of all other products sold by the same firm, the sum of the characteristics of all products sold by rival firms and the average of the characteristics of all products that are available at that date. To raise the variation of the instruments, we compute them within each of the five beer type categories. The same practice has been adopted by Bresnahan et al. (1997). In addition, we exploit our knowledge of the retail monopoly's pricing rule, (9), and exogenous changes in alcohol excise taxes, the monopoly's markup and the deposit charged for each packaging type. For each of the dates, where one of these price components is changed, we compute counterfactual prices that hold the tax rates and deposit charges constant at the previous period's values and use the imputed prices as instruments. ${ }^{12}$ The advantage of these instruments is that they vary at the product level and rely on decisions taken at the government level, as both the alcohol excise tax and the retail monopoly's markup are controlled by Swedish parliament and not the beer producers and wholesalers.

\footnotetext{
${ }^{12}$ In May 1996, both the retail monopoly's markup and the deposit charges are changed. The alcohol excise tax is altered in January 1997 and January 1998. The remaining exogenous change in the retailer's markup is in January 2000.
} 
With regard to the BLP instruments, we only include the taste attributes, richness, sweetness and bitterness, as well as alcohol content from the observable product characteristics. The remaining observable attributes are either dummy variables or take on non-zero values for only a small number of the products (advertising expenditure). This selection ensures that we obtain instruments with sufficient variation across both individual products and firms.

Table 4 lists all the excluded instruments and their correlation with price. The remaining columns of the instrument matrix $Z$ are the observable characteristics listed in Table 1.

For the majority of the excluded instruments the magnitude of their correlation with price is around .3, indicating that they can qualify as relevant. To examine whether the instruments fulfill this requirement, Table 5 presents the results of regressing the excluded instruments only and all instruments on price, respectively. The former regression explains 37 percent of the variation in price and the excluded instruments are jointly significant as implied by the value of the F-statistic. When utilizing the included instruments as well, the regressors explain 71 percent of the variation in price, the instruments are jointly significant and, with two exceptions, the included instruments do not drive out the excluded ones.

To address the question of validity, we test the overidentifying restrictions imposed by the instruments. The bottom panel of Table 6 shows the values of the Sargan statistic for the instrumental variables regression, and the value of the J-statistic for the BLP model estimated by efficient GMM. For both specifications, we do not reject the null of the instruments being orthogonal to the residuals. We conclude that our instruments are both relevant and valid for the data at hand.

\subsection{Estimation Results}

We first discuss the logit and instrumented logit results that we report in Table 6 . In both specifications, the price coefficient is negative and statistically significant. The instrumented price coefficient is more than two times as large as its uninstrumented counterpart, which tells us that endogeneity of prices in our data is a substantial issue. This is mirrored in the mean own-price elasticities at the bottom of the table. According to the logit estimation, demand is not very elastic with own-price elasticities spread around 2. In the instrumented logit and BLP models, the average elasticity rises to 5 and 5.6, respectively. This value is close to previously reported demand estimates for beer in Hausman et al. (1995) and Slade (2004). Moreover, the implied wholesale/producer markups of around 40 percent (see Table 7) correspond quite closely to the estimates of Goldberg and Hellerstein (2012).

The average cross-price elasticity in the logit model is less than half in magnitude than the average cross-price elasticity in the instrumented logit specification. In the BLP model, the substitutability between products is higher still. This is an effect that we would like to see, because the BLP model allows cross-price elasticities between products to be influenced by 
product characteristics, while the standard logit model pins down the substitution patterns with observable market shares only.

We find strong evidence of heterogeneity in Swedish beer consumers' tastes. The estimated standard deviations of the random coefficients are large and statistically significant at the 95 percent confidence level. Figure 3 plots the implied distributions of the random coefficients. In the tails of the distribution for the price coefficient, there are some consumers that are almost irresponsive to price, while others are roughly twice as sensitive to price as the mean of the distribution. Looking at the other coefficients, the majority of consumers values higher alcoholic content and dislikes relatively sweet beers.

\subsection{Elasticities, Markups and Substitution Patterns}

To examine our estimates more closely, we turn to the implied product level markups and present an excerpt from the elasticity matrix determining the substitutability of all products in November 2000, the month prior to the official clearing of the merger by the Swedish competition authority.

Table 7 summarizes the computed markups for both the instrumented logit and the random coefficients logit models. To back out markups at the producer-/wholesale-level we use full knowledge of the retail monopoly's pricing rule, (9). The estimated average markup of around 40 percent is quite close to that reported by Goldberg and Hellerstein (2012), who estimate a random coefficients logit model for beer demand in the greater Chicago metropolitan area. For both specifications, the number of economic outliers, i.e. beers with markups greater than 1 , is negligible with less than half a percent of all observations.

To get a better impression of how reasonable the estimated substitution patterns are, we look at a subset of beers and present the estimated substitution patterns between these beers. We chose from among the best-selling beers of Carlsberg, Pripps and domestically competing firms (Spendrups and Kopparbergs), as well as some internationally better known beer varieties.

Table 8 presents the beers we picked along with most of their observable characteristics. The estimated own- and cross-price elasticities for these products are shown in Table 9 as an excerpt of the elasticity matrix for November 2000. There are three beers with a relatively high alcoholic content, namely Pripps Extra Stark, Arboga 7.7 and Falcon Strong. The latter two beers are very similar in their taste attributes, as they are both very rich and bitter in taste, while Pripps Extra Stark's taste profile is much closer to those of the other beers in the selection.

Looking at Table 9, we can compare how substitutable these three beers are among each other and with respect to the remaining products for both the BLP and instrumented logit models. In the latter, these three beers are not identified as very close substitutes. Instead, the beer with the highest market share (Lapin Kulta) is the best substitute, even though it is located farther away in characteristics space than the other high alcohol varieties. In the BLP model, however, these three beers are close substitutes among each other and they are not very substitutable 
with respect to the other beers in our selection.

The average taste characteristics over all beers that are offered in November 2000 are 5.8 in richness, 2.2 in sweetness, 6.3 in bitterness and an alcoholic content of 5.5 percent of volume, while the average market price for a liter of beer is 32 SEK. Given these numbers, it is clear that the remaining beers in our selection are quite close to the average beer in the sample, with the exception of Staropramen that has a high value in bitterness and Kopparbergs Original, which has a low alcoholic content and a very low price. These two beers are therefore more differentiated than the other mainstream beers. This is mirrored in our BLP estimates. Based on these and similar comparisons, we find that our BLP model estimates deliver substitutability patterns that are intuitive and in line with product locations in characteristics space.

\section{Merger Simulation}

Having backed out product-level marginal cost estimates, we can address our question of interest: what would post-merger prices have been, had the Swedish competition authority required no divestitures from the merging parties? We thus compare two scenarios. In the first, we simulate counterfactual post-merger prices under the assumption that Carlsberg and Pripps retain all of their product holdings. In the second scenario, we simply impose the actual post-merger ownership pattern. That is, the ownership of the divested beers is transferred to Galatea.

The inputs for the simulations are the outcomes of our demand estimation and the observed equilibrium outcomes in November 2000, which is the month immediately prior to the official clearing of the merger by the Swedish competition authority.

We take the estimates of marginal costs, $\widehat{m c}$, and unobserved product characteristics, $\xi$, as given in our simulations. The post-merger wholesale equilibrium prices, $\widetilde{p}^{w}$, solve

$$
\widetilde{p}^{w}=\widehat{m c}-\widetilde{\Omega}^{-1}\left(\widetilde{p}^{r}\right) \widetilde{s}\left(\widetilde{p}^{r}\right) \kappa^{-1}
$$

where the entries in $\widetilde{\Omega}$ reflect the respective post-merger ownership patterns in the two scenarios. We solve for the counterfactual prices by iterating over (14). The observed retail prices in November 2000 serve as our initial guess. Plugging these prices into the right-hand side of (14) yields the wholesale prices of the next iteration. We then simply apply the retail monopolist's pricing rule, (9), to compute the corresponding retail prices and continue until convergence. This procedure simply iterates over firm's best responses to the post-merger ownership changes. Once converged, no firm has an incentive to deviate from the computed equilibrium prices.

\subsection{Results}

The two scenarios deliver starkly contrasting results. Table 11 presents the post-merger price changes averaged for the different parties involved in the merger. If Carlsberg and Pripps are 
allowed to retain all of their product holdings, Carlsberg is predicted to raise the prices of its beers by on average roughly 4.5 percent, while Pripps increases its prices by on average about nine percent. The beers that the Swedish competition authority required to be divested in the actual merger behave very much in line with the other products owned by the merging parties. On average their prices are predicted to rise by about five percent. Given that 16 of the 19 divested beers are owned by Carlsberg this outcome is intuitive. Galatea's prices, on the other hand, are flat, if it does not acquire parts of Carlsberg's and Pripps' product portfolios.

When the divestitures are imposed, the pricing patterns are reversed. Carlsberg lowers the prices of its remaining products by about three percent, while Pripps holds its prices constant. Galatea, however, derives more market power from enlarging its holdings of beers. The prices of the products that were owned by Galatea before the merger are raised by about two percent, while the new products in its portfolio, the divested beers, are predicted to lower their prices by more than five percent.

There are two noteworthy asymmetries in the merger. Pripps gains more market power than Carlsberg in the merger, as it raises its prices more strongly than Carlsberg. With the divestitures, Galatea raises prices on the beers it already held in its ownership pre-merger, while it reduces prices on the additional beers it acquires post-merger. The key to understanding these effects is that price changes depend on the portfolio composition and number of brands that firms control. Table 10 shows that in the case of no divestitures, Carlsberg brings 46 products to the table, while Pripps only holds 27 beer varieties. In the case with divestitures, the respective number of products are 30 and 24, respectively. As a result, Pripps' products gain more crossprice effects post-merger and therefore derive greater pricing power than those of Carlsberg. This holds for both the actual and the counterfactual merger and explains the asymmetry in the magnitude of Carlsberg's and Pripps' price responses following the merger. With regard to the asymmetric price responses of Galatea's products post-merger, we can again refer back to Table 10. We can see that Galatea's product portfolio before the merger was tiny in terms of market shares. These beer brands therefore do not offer any substantial cross-price effects to the divested products that are added to Galatea's holdings. As a consequence, the divestitures reduce prices following the merger, while Galatea's previously held products derive additional market power from the new product additions and raise their prices, instead. In the following sub-section we will make the intuition behind these effects explicit by considering the upward pricing pressure associated with different mergers in a stylized setting.

Before doing that, let us re-examine observed price movements surrounding the merger that we documented in Section 3.1.2. Overall the simulations capture that price responses were limited, that prices of divested beers fell and that prices of other beers in the Galatea portfolio increased. There are minor differences, because the simulations predict Carlsberg's product prices to fall while in the data they increased slightly post-merger. We need to keep in mind that our merger simulation assumes that all other variables are kept constant at their November 2000 level and that there are no additional perturbations to the unobserved product characteristics (the $\xi$ 's). This assumption is standard in the literature (see Nevo 2000a, for instance and Berry and Pakes 
(2001) for a detailed discussion) and an obvious abstraction from reality. It is therefore not surprising that our simulated outcomes stray somewhat from the actually observed outcomes. Nevertheless, we find the fact that the merger simulation can capture the difference in pricing behavior between the divested products and the beers retained by the merging parties encouraging and argue that it highlights the potential value of merger simulations in the settling of merger cases.

With falling prices and fewer products sold one may ask if the merger was profitable. Our simulations are less precise with regards to profits than they are with respect to prices and the confidence band on profits includes zero. More importantly, the divested brands were sold rather than given away and the sales price is unknown to us. We should also note that this was part of a larger merger in several national markets and finally there may be cost savings associated with the merger that we disregard. Indeed, in 2004 Carlsberg shifted the production of several Swedish brands from Sweden to Denmark.

As the lower panel of Table 11 shows, we can unambiguously rank the implied changes in consumer welfare for the two scenarios. Without imposing divestitures consumers lose about .4 SEK per purchase, which is roughly one percent of the average sale price. At the aggregate market level, this sums to a monthly cost of roughly 3.6 million SEK. When the divestitures are imposed, consumers on average gain about .12 SEK per purchase, which sums to an aggregate monthly gain in consumer welfare of roughly 1.14 million SEK. Using a standard bootstrap procedure, we find that these effects are statistically significant at the 95 percent confidence level.

\subsubsection{Divestitures Matter for Post-Merger Price Increases}

To provide some further intuition for the effects on prices in simulations we adapt the concept of upward pricing pressure (UPP) as developed by Farrell and Shapiro (2010) to show that a merger between two firms does not necessarily lead to uniform price increases. This is well-known with regard to cost synergies between the merging parties. If marginal costs of production fall sufficiently, post-merger prices can be below or at their pre-merger level. We abstract from synergy gains, however, and instead focus on the role of divestitures.

To be concise, we present a very stylized example. Suppose there are only two firms, where firm 1 owns two products, $j$ and $k$, while firm 2 sells variety $l$. Then the first-order conditions of the firms' profit maximization problems are as follows. ${ }^{13}$

$$
\begin{aligned}
& p_{j}=m c_{j}-\left(\frac{\partial s_{j}}{\partial p_{j}}\right)^{-1}\left(s_{j}+\frac{\partial s_{k}}{\partial p_{j}}\left(p_{k}-m c_{k}\right)\right) \\
& p_{l}=m c_{l}-\left(\frac{\partial s_{l}}{\partial p_{l}}\right)^{-1} s_{l}
\end{aligned}
$$

\footnotetext{
${ }^{13}$ The first-order condition for $k$ is analogous to that for $j$.
} 
With product prices being strategic complements, the cross-price effect $\partial s_{k} / \partial p_{j}$ is positive. In response to a price increase of product $j$, a fraction of its consumers substitute away to product $k$. The multi-product firm 1 internalizes this effect and can therefore attain higher prices for both products $j$ and $k$ as compared to the case when each product is owned by a separate firm. We can now think about two cases that are directly related to the outcomes of the CarlsbergPripps merger and our counterfactual simulations. First, suppose that firms 1 and 2 merge and that no divestitures are required. We use this example to understand why prices of Pripps increase by more in the counterfactual merger where all products are kept. The optimal postmerger prices of varieties $j$ and $l, \widetilde{p}_{j}$ and $\widetilde{p}_{l}$, satisfy the following conditions.

$$
\begin{aligned}
& \widetilde{p}_{j}=m c_{j}-\left(\frac{\partial s_{j}}{\partial p_{j}}\right)^{-1}\left(s_{j}+\frac{\partial s_{k}}{\partial p_{j}}\left(p_{k}-m c_{k}\right)+\frac{\partial s_{l}}{\partial p_{j}}\left(p_{l}-m c_{l}\right)\right) \\
& \widetilde{p}_{l}=m c_{l}-\left(\frac{\partial s_{l}}{\partial p_{l}}\right)^{-1}\left(s_{l}+\frac{\partial s_{j}}{\partial p_{l}}\left(p_{j}-m c_{j}\right)+\frac{\partial s_{k}}{\partial p_{l}}\left(p_{k}-m c_{k}\right)\right)
\end{aligned}
$$

We now define the instantaneous pricing pressure at the product-level as the difference between the post- and pre-merger first-order conditions, $\Delta p_{j} \equiv \widetilde{p}_{j}-p_{j}$. To do so, we evaluate the post-merger first-order conditions at pre-merger prices. This makes clear that UPP is an approximation to a merger simulation. We do not solve for post-merger equilibrium prices, but pin down the direction of price changes following the merger. Differences in pricing pressures also point to which product adjusts its price more or less strongly post-merger.

$$
\begin{aligned}
\frac{\Delta p_{j}}{p_{j}} & =-\hat{\eta}_{j}^{-1} \frac{\partial s_{l}}{\partial p_{j}}\left(p_{l}-m c_{l}\right)>0 \\
\frac{\Delta p_{l}}{p_{l}} & =-\hat{\eta}_{l}^{-1}\left(\frac{\partial s_{j}}{\partial p_{l}}\left(p_{j}-m c_{j}\right)+\frac{\partial s_{k}}{\partial p_{l}}\left(p_{k}-m c_{k}\right)\right)>0
\end{aligned}
$$

$\Delta p_{j} / p_{j}$ is the net relative price change in response to the merger and $\hat{\eta}_{j} \equiv\left(\partial s_{j} / \partial p_{j}\right) p_{j}$ is the semi-elasticity of demand for beer $j$ and gives the change in market share of $j$ in response to a one percent change in $j$ 's price.

The product-level pricing pressure of product $j$ measured as a net percentage change is driven by two components: its own-price elasticity and the diverted profit margin from its former competitor product $l$. Only the diverted margin of the former rival matters, because we are evaluating each firm's price response to the merger at pre-merger prices. The diversion effect stemming from products that were owned before the merger is thereby netted out. Therefore, the price adjustment of product $l$ is driven by two profit diversion terms and not one, as is the case for both of firm 1's products. If the individual diversion terms for $j$ and $l$ are of similar magnitude and absent substantial differences between the two products' own-price elasticities, $l$ 's price is adjusted upward more strongly than that of $j$.

Thus, if two firms merge and their product holdings are 'similar' to each other in terms of their 
markups and how substitutable they are with respect to each other, it will likely be the case that the merging party with fewer products in its portfolio adjusts its prices more strongly postmerger - pointing to the intuition for the stronger price increase of Pripps beers in the simulation without divestitures. When there are no divestitures we thus also have an intuitive result that there is an upward pricing pressure on all products post-merger.

To shed some light on the effect of divestitures, consider a second case where firms 1 and 2 are cleared to merge under the condition that product $k$ is divested as an independent rival firm. Applying the above to this case yields the pricing pressures for each of the products.

$$
\begin{aligned}
\frac{\Delta p_{j}}{p_{j}} & =-\hat{\eta}_{j}^{-1}\left(\frac{\partial s_{l}}{\partial p_{j}}\left(p_{l}-m c_{l}\right)-\frac{\partial s_{k}}{\partial p_{j}}\left(p_{k}-m c_{k}\right)\right)<>0 \\
\frac{\Delta p_{k}}{p_{k}} & =-\hat{\eta}_{k}^{-1}\left(-\frac{\partial s_{j}}{\partial p_{k}}\left(p_{j}-m c_{j}\right)\right)<0 \\
\frac{\Delta p_{l}}{p_{l}} & =-\hat{\eta}_{l}^{-1} \frac{\partial s_{j}}{\partial p_{l}}\left(p_{j}-m c_{j}\right)>0
\end{aligned}
$$

We first note that the price of the divested product $k$ falls. Its pricing now does not consider the diverted profit margin to product $j$ and there is a downward pressure on its price. The sign of the price change for product $j$ is ambiguous. If the diverted profits from variety $k$ exceed those of the new addition to firm 1's portfolio, product $l$, the merged firm finds it optimal to reduce the price of brand $j$ following the merger. As before, the price of product $l$ unambiguously rises post-merger, because it benefits from the diverted profit margin stemming from variety $j$. In terms of the Carlsberg-Pripps merger this analysis highlights why it is possible to see a fall in the prices of Carlsberg's beers in the simulations with divestitures and why Pripps' prices are roughly flat (since most of the divested beers were from Carlsberg its pricing pressure is more closely captured by product $j$ and Pripp's pricing pressure more closely captured by product $l$ ). Thus, our example shows that properly chosen divestitures can induce falling prices for the divested varieties, and if the divestitures are sufficiently important in terms of their diverted profit margins, it is also possible that prices of the merging parties' products are lowered following the merger.

\subsection{The Identity of the Firm Gaining Control of the Divestitures Matters}

Having established that divestitures can limit price increases following a merger, we assess how much market outcomes are affected when a different firm gains control of the divestitures. Before the merger, Galatea's market share was negligible. As a contrasting exercise, we simulate the counterfactual outcomes when Spendrups receives the divestitures, instead. Spendrups is the third largest producer in the market and accounts for almost a fifth of total sales in November 2000. 
Given our findings from the previous section, we would expect that the downward pricing pressure produced by the divestitures in this alternative scenario is muted. The simulation results are shown in Table 12 and confirm this intuition. The divestitures are still predicted to lower prices post-merger, but the drop is now less than two percent as compared to a more than five percent price reduction when Galatea gains control over the divestitures. Spendrups is predicted to raise prices on the products it owned pre-merger by more than one percent. Pripps' prices are still flat, even though the mean of the price response following the merger shifts to the right. Similarly, the drop in the prices of Carlsberg's beers is muted. The same holds for the market average.

These effects directly translate to consumer surplus. Consumers' still gain slightly following the merger, but the effect is substantially reduced. Consumers gain on average .04 SEK per purchase, summing to an aggregate monthly gain in consumer surplus of roughly .37 million SEK. These results highlight that the identity of the buyer matters for the expected price effects. Note also that here we only consider unilateral effects - to the extent that coordinated effects are a concern (as analyzed by Compte, Jenny and Rey (2002)) it becomes even more important to find a buyer that is a small player in the market.

\section{Conclusion}

We have estimated a BLP demand model for the Swedish beer market to simulate the effects of the merger between Carlsberg and Pripps in February 2001. Our simulated price responses to the actual merger capture the post-merger pricing patterns well. The overall effect on prices is limited, while the beers that were required to be divested to a small rival firm lower their prices. We thereby demonstrate that divestitures can generate downward pricing pressure following a merger. The divestitures account for about six percent of total sales volume and are thereby substantial in terms of size.

To gain further insight into the effect, we conduct two counterfactual merger simulations. First, we simulate the effect on market outcomes when no divestitures are imposed. This scenario yields the intuitive outcome that the prices of the merging parties' products are raised substantially. Pripps raises its prices on average by more than nine percent, while Carlsberg increases prices by about four percent. Second, instead of letting Galatea, which before the merger accounted for a negligible share of total sales, gain control of the divested beers, we let Spendrups, the third largest producer in the market, absorb them into its holdings. In this scenario, the pricereducing effect of the divestitures is roughly reduced to a third of its magnitude in the actual merger.

We can therefore conclude that divestitures matter for the likely price effects of a cleared merger. Moreover, the identity of the rival firm that gains control over the divested products is important for the impact of any divestiture requirement. The fact that Galatea added the divestitures to its product portfolio in the Carlsberg-Pripps merger certainly aided in keeping price rises in 
check following the merger.

Our findings highlight the usefulness of divestitures as a tool for competition policy in the merger review process. Specifically, merger simulations can serve as a guide to competition authorities to identify the specific set of divested products that can keep prices down post-merger and the best recipient for the divestitures among the incumbent rivals of the merging parties.

\section{References}

Angrist, Joshua D., and Pischke, Jörn-Steffen, (2010), "The Credibility Revolution in Empirical Economics: How Better Research Design Is Taking the Con out of Econometrics," Journal of Economic Perspectives, 24, issue 2, p. 3-30.

Ashenfelter, Orley C. and Hosken, Daniel S., (2011), "The Effect of Mergers on Consumer Prices: Evidence from Five Selected Case Studies, " forthcoming in Journal of Law and Economics.

Ashenfelter, Orley C.,Hosken, Daniel S. and Weinberg, Matthew, (2009), "Generating Evidence to Guide Merger Enforcement," CPI Journal, Competition Policy International, vol. 5.

Asplund, Marcus, Friberg, Richard and Wilander, Fredrik, (2007), "Demand and Distance: Evidence on Cross-Border Shopping," Journal of Public Economics, 91, issue 1-2, p. 141-57.

Baker, Jonathan B. and Bresnahan, Timothy F., (1985), "The Gains from Merger or Collusion in ProductDifferentiated Industries," Journal of Industrial Economics, 33, issue 4, p. 427-44.

Benkard, Lanier, Bodoh-Creed, Aaron and Lazarev, John, (2010), "Simulating the Dynamic Effects of Horizontal Mergers: U.S. Airlines," Manuscript, Yale University.

Berry, Steven (1994), "Estimating Discrete-Choice Models of Product Differentiation," RAND Journal of Economics, 25, issue 2, p. 242-62.

Berry, Steven, James Levinsohn and Ariel Pakes, (1995), "Automobile Prices in Market Equilibrium," Econometrica, pp. 841 - 890.

Berry, Steven and Ariel Pakes, (2001), "Comments on "Alternative Models of Demand for Automobiles" by Charlotte Wojcik," Economics Letters, 74, issue 1, pp. 43 - 51. 
Björnerstedt, Jonas and Verboven, Frank (2012), "Does Merger Simulation Work? A 'Natural Experiment' in the Swedish Analgesics Market," Manuscript, KU Leuven.

Bresnahan, Timothy F., Scott Stern and Manuel Trajtenberg, (1997), "Market Segmentation and the Sources of Rents from Innovation: Personal Computers in the Late 1980s," RAND Journal of Economics, pp. $17-44$.

Carlton, Dennis, (2009), "Why We Need to Measure the Effect of Merger Policy and How to Do It," CPI Journal, Competition Policy International, vol. 5.

Compte, Olivier, Frédéric Jenny and Patrick Rey (2002), "Capacity constraints, mergers and collusion," European Economic Review pp.1-29.

Cosnita, Andreea and Jean-Philippe Tropeano, (2009), "Negotiating Remedies: Revealing the Merger Efficiency Gains," International Journal of Industrial Organization pp.188-196.

DG Competition, (2005), "Merger Remedies Study," European Commission.

Dubé, Jean-Pierre, Jeremy T. Fox, and Che-Lin Su, (2012), "Improving the Numerical Performance Static and Dynamic Aggregate Discrete Choice Random Coefficients Demand Estimation,” Econometrica, pp. $2231-2267$.

Einav, Liran, and Levin, Jonathan, (2010), "Empirical Industrial Organization: A Progress Report," Journal of Economic Perspectives, 24, issue 2, p. 145-62.

Elzinga, Kenneth G., (1969), "The Antimerger Law: Pyrrhic Victories?,” Journal of Law and Economics, pp.43-78.

European Commission (2008), "Notice on Remedies Acceptable under Council Regulation (EC) No 139/2004 and under Commission Regulation (EC) No 802/2004".

Farrell, Joseph and Carl Shapiro, (2010), "Antitrust Evaluation of Horizontal Mergers: An Economic Alternative to Market Definition," The B.E. Journal of Theoretical Economics. 
Federal Trade Commission (1999), "A Study of the Commission's Divestiture Process," Staff Report, Federal Trade Commission.

Focarelli, Dario and Panetta, Fabio, (2003), "Are Mergers Beneficial to Consumers? Evidence from the Market for Bank Deposits," American Economic Review, 93, p. 1152-72.

Goldberg, Pinelopi K. and Rebecca Hellerstein, (2012), "A Structural Approach to Identifying the Sources of Local Currency Price Stability," Review of Economic Studies, pp. 1 - 36.

Hastings, Justine S., (2004), "Vertical Relationships and Competition in Retail Gasoline Markets: Empirical Evidence from Contract Changes in Southern California," American Economic Review, 94, issue 1, p. $317-28$.

Hausman, Jerry, Leonard, Gregory and Zona, J. Douglas, (1994), "Competitive Analysis with Differentiated Products," Annales D'Economie Et De Statistique, 34, p. 160-80.

Hellerstein, Rebecca, (2008), "Who Bears the Cost of a Change in the Exchange Rate? Pass-Through Accounting for the Case of Beer," Journal of International Economics, 76, issue 1, p. 14-32

Knittel, Christopher R. and Konstantinos Metaxoglou, (2012), "Estimation of Rancom Coefficient Demand Models: Two Empiricists' Perspective," forthcoming in The Review of Economics and Statistics.

Motta, Massimo, (2004), "Competition policy. Theory and Practice," Cambridge: Cambridge University Press.

Nevo, Aviv, (2000a), "Mergers with Differentiated Products: The Case of the Ready-to-Eat Cereal Industry," RAND Journal of Economics, pp. 395 - 421.

Nevo, Aviv, (2000b), “A Practitioner's Guide to Estimation of Random-Coefficients Logit Demand Models," Journal of Economics and Management Strategy, pp. 513 - 548.

Pesendorfer, Martin, (2003), "Horizontal Mergers in the Paper Industry," RAND Journal of Economics, 34, p. $495-515$. 
Peters, Craig, (2006), "Evaluating the Performance of Merger Simulation: Evidence from the U.S. Airline Industry," Journal of Law and Economics, 49, p. 627-49.

Petrin, Amil, (2002), "Quantifying the Benefits of New Products: The Case of the Minivan," Journal of Political Economy, 110, issue 4,p. 705-29.

Pinkse, Joris and Slade, Margaret E., (2004), "Mergers, Brand Competition, and the Price of a Pint," European Economic Review, 48, p. 617-43.

Rojas, Christian, (2008), "Price Competition in U.S. Brewing," Journal of Industrial Economics, 61, issue 1, p. 1-31.

Soetevent, Adriaan R. , Marco A. Haan, and Pim Heijnen, (2009), "Do Auctions and Forced Divestitures increase Competition?," Tinbergen Institute Discussion Paper

Su, Che-Lin and Kenneth Judd, (2012), "Constrained Optimization Approaches to Estimation of Structural Models," Econometrica, pp. 2213 - 2230.

Taylor, Cristopher T. and Hosken, Daniel S., (2007), "The Economic Effects of the Marathon-Ashland Joint Venture: The Importance of Industry Supply Shocks and Vertical Market Structure," Journal of Industrial Economics, 60, issue 3, p. 419-51.

Tenn, Steven and Yun, John M., (2011), "The Success of Divestitures in Merger Enforcement: Evidence from the J\&J Pfizer Transaction," International Journal of Industrial Organization, pp. 273-282.

Vasconselos, Helder, (2010), "Efficiency Gains and Structural Remedies in Merger Control," International Journal of Industrial Organization, pp. 742-766.

Weinberg, Matthew C., (2011), "More Evidence on the Performance of Merger Simulations," American Economic Review, Papers and Proceedings, p. 51-55.

Weyl, Glen E. and Sonia Jaffe, (2012), "The First-Order Approach to Merger Analysis," Harvard Economics Department Working Paper. 
Whinston, Michael, (2006), "Lectures on antitrust economics," MIT Press, Cambridge (MA). 


\section{$9 \quad$ Figures and Tables}

Table 1: Observable Product Attributes

\begin{tabular}{l|c|c} 
& Mean & Std. Dev. \\
\hline \hline Price per Liter (SEK) & 34.30 & 7.96 \\
\hline Richness & 5.68 & 1.81 \\
\hline Sweetness & 2.21 & 1.33 \\
\hline Bitterness & 6.16 & 2.10 \\
\hline Alcohol as \% of Vol. & 5.36 & .95 \\
\hline Advertising (mln SEK) & .12 & .69 \\
\hline Foreign & .42 & - \\
\hline Bottle $(50 \mathrm{cl})$ & .30 & - \\
\hline Bottle $(33 \mathrm{cl})$ & .37 & - \\
\hline Can $(33 \mathrm{cl})$ & .07 & - \\
\hline Ale & .10 & - \\
\hline Dark Lager & .04 & - \\
\hline Stout & .03 & - \\
\hline Weissbeer & .02 & - \\
\hline \hline
\end{tabular}

Richness, sweetness and $\overline{\text { bitterness are all measured on a scale from } 1 \text { to }} 12$. The scores for these attributes are determined by Systembolaget, the alcohol retail monopoly, and published in its freely available catalogues. For dummy variables only the mean or fraction of all observations for which the dummy takes on a value of 1 is reported. The base category for the different kinds of packaging is the $50 \mathrm{cl}$ can. The light lager segment is the base category for the different types of beer available. 


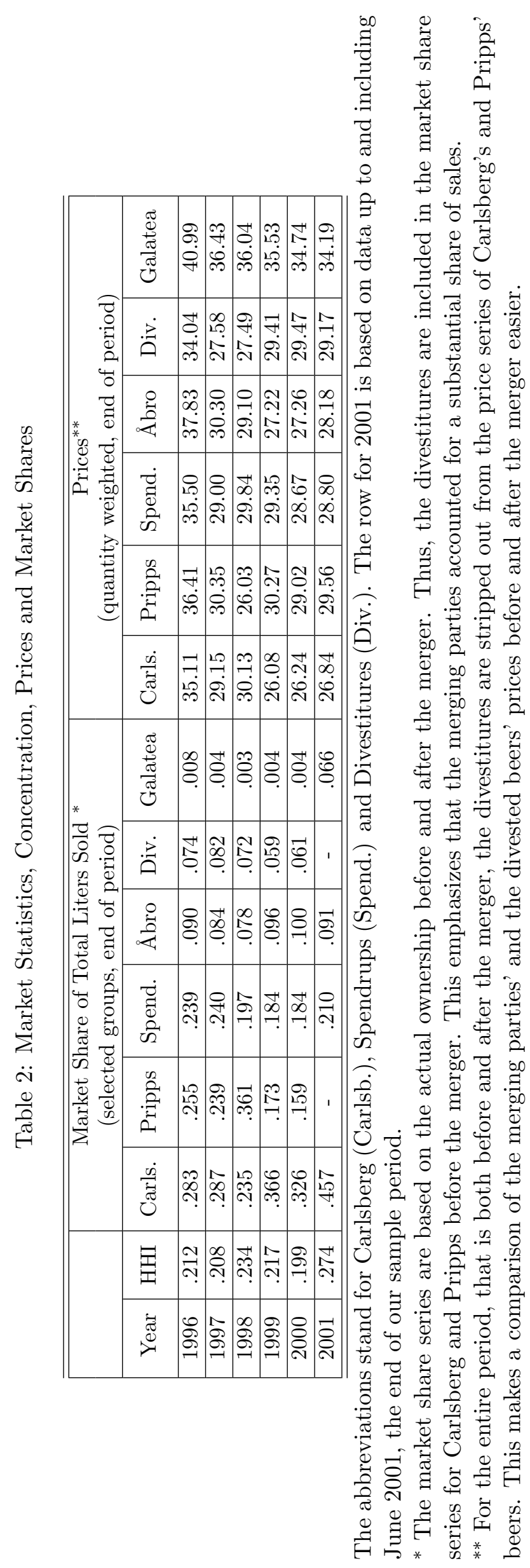




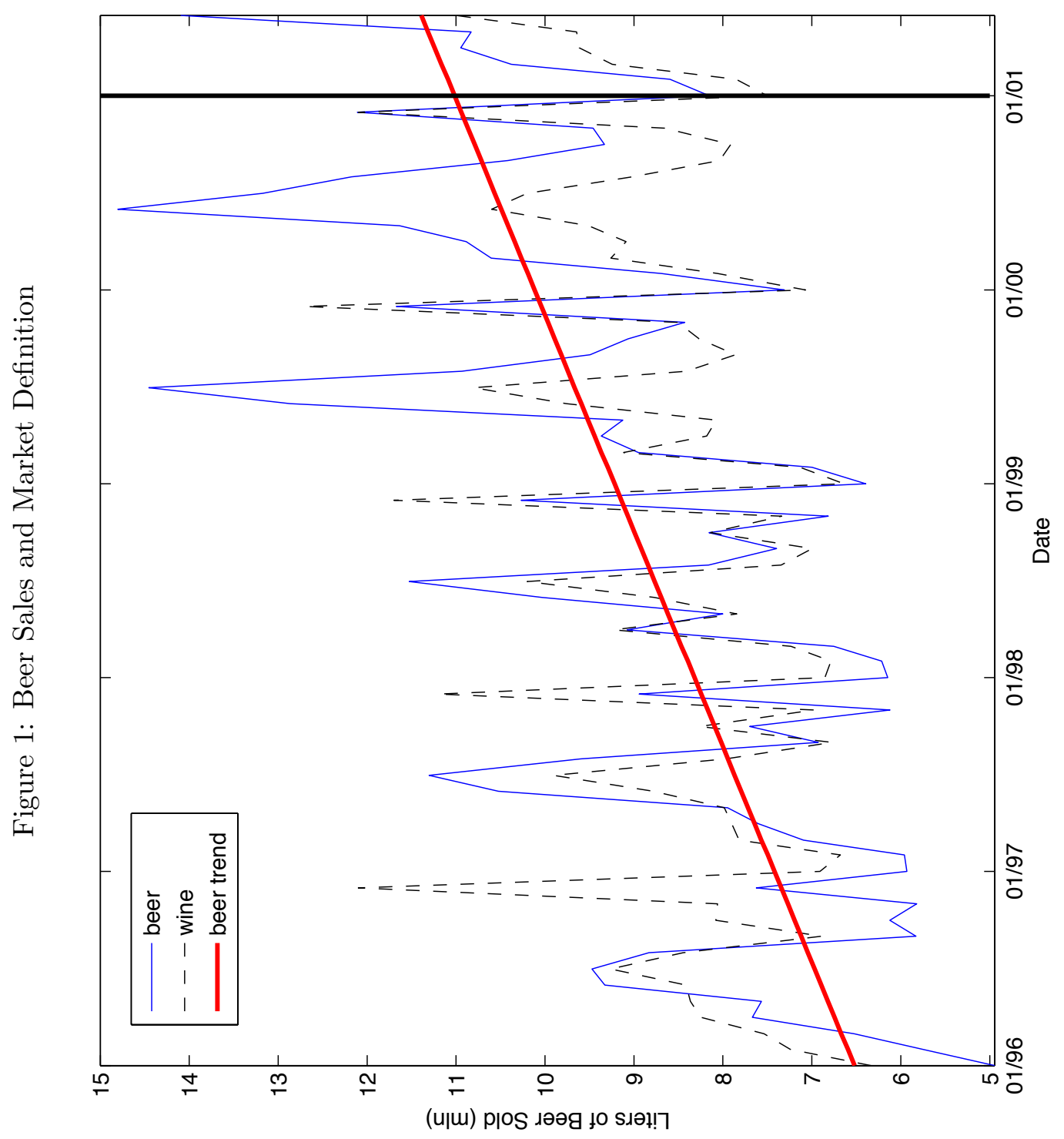




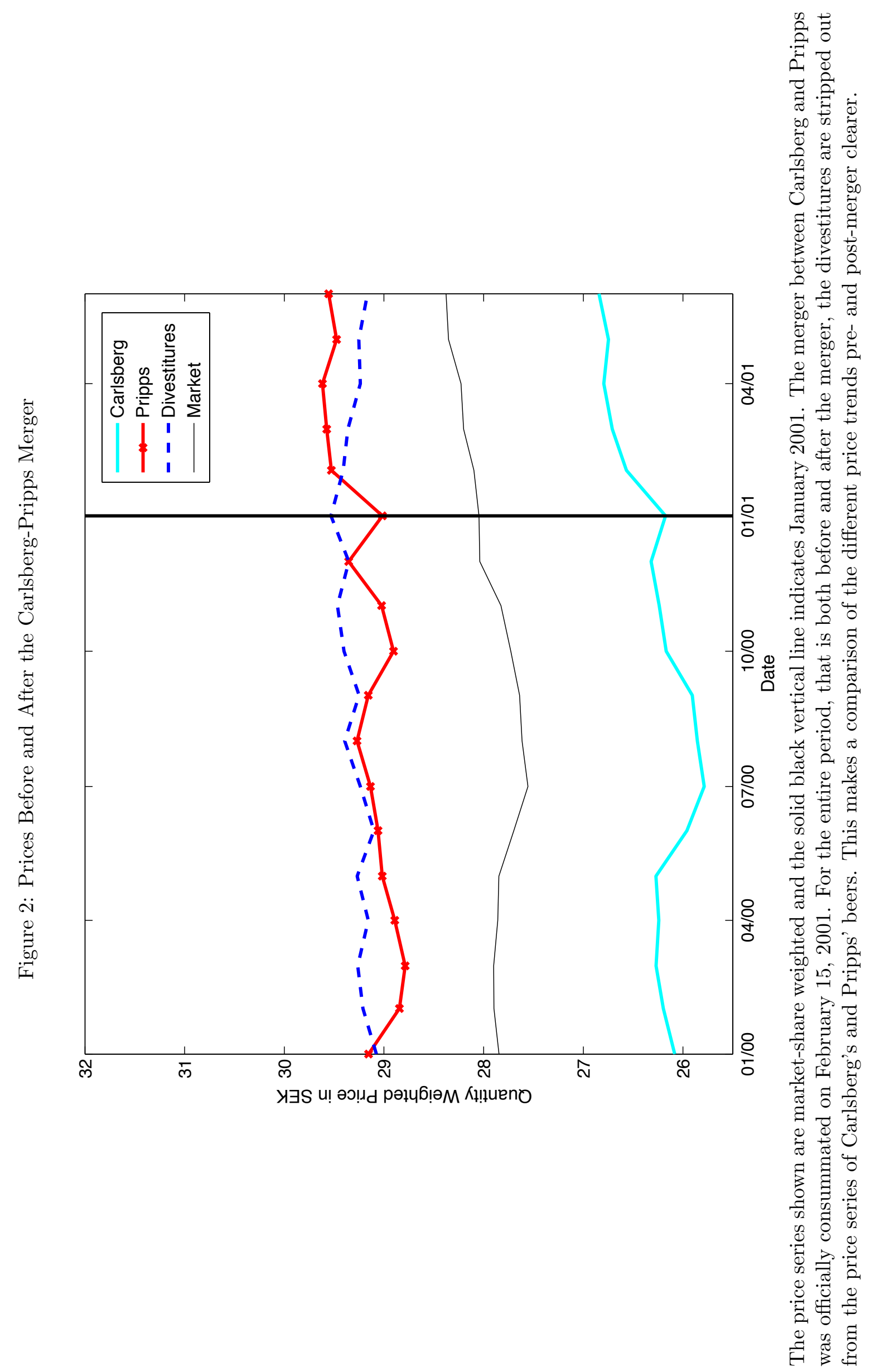


Table 3: Correlation Patterns of Prices Before and After the Carlsberg-Pripps Merger

\begin{tabular}{|l|c|c|c|c|}
\hline & \multicolumn{4}{|c|}{ January 2000 to November 2000 } \\
\hline & All & Carlsberg & Pripps & Divestitures \\
\hline All & 1 & - & - & - \\
\hline Carlsberg & .92 & 1 & - & - \\
\hline Pripps & -.72 & -.78 & 1 & - \\
\hline Divestitures & -.17 & .10 & .02 & 1 \\
\hline \hline & \multicolumn{5}{|c|}{ February 2001 to June 2001 } \\
\hline & All & Carlsberg & Pripps & Divestitures \\
\hline & 1 & - & - & - \\
\hline All & .58 & 1 & - & - \\
\hline Carlsberg & -.67 & .21 & - & - \\
\hline Pripps & -.76 & -.95 & .08 & 1 \\
\hline Divestitures & -.76 &
\end{tabular}

The upper diagonal elements of the correlation matrices are not reported due to symmetry. The correlations are computed based on the market share weighted price series for each of the groups in the Table. As in Figure 2 both before and after the merger the divestitures are stripped out of the price series for Carlsberg's and Pripps' beers.

Table 4: Correlation of the Excluded Instruments with Price

\begin{tabular}{l|l|r|l|l|r} 
Instrument & Computation & $\rho_{z, p}$ & Instrument & Correlation & $\rho_{z, p}$ \\
\hline \hline$z_{j t, 1}$ & $\widetilde{p}_{k t, m k}$ & .101 & $z_{j t, 9}$ & $\sum_{j \notin \mathcal{F}} x_{j t, 3}$ & -.462 \\
\hline$z_{j t, 2}$ & $\widetilde{p}_{j t, d}$ & .142 & $z_{j t, 10}$ & $\sum_{j \notin \mathcal{F}} x_{j t, 4}$ & -.468 \\
\hline$z_{j t, 3}$ & $\widetilde{p}_{j t, \tau^{a}}$ & .017 & $z_{j t, 11}$ & $\sum_{j \notin \mathcal{F}} x_{j t, 5}$ & -.468 \\
\hline$z_{j t, 4}$ & $\sum_{j \in \mathcal{F}} x_{j t, 2}$ & -.302 & $z_{j t, 12}$ & $J_{t}^{-1} \sum_{j=1}^{J_{t}} x_{j t, 2}$ & .394 \\
\hline$z_{j t, 5}$ & $\sum_{j \in \mathcal{F}} x_{j t, 3}$ & -.328 & $z_{j t, 13}$ & $J_{t}^{-1} \sum_{j=1}^{J_{t}} x_{j t, 3}$ & .223 \\
\hline$z_{j t, 6}$ & $\sum_{j \in \mathcal{F}} x_{j t, 4}$ & -.316 & $z_{j t, 14}$ & $J_{t}^{-1} \sum_{j=1}^{J_{t}} x_{j t, 4}$ & .263 \\
\hline$z_{j t, 7}$ & $\sum_{j \in \mathcal{F}} x_{j t, 5}$ & -.324 & $z_{j t, 15}$ & $J_{t}^{-1} \sum_{j=1}^{J_{t}} x_{j t, 5}$ & -.020 \\
\hline$z_{j t, 8}$ & $\sum_{j \notin \mathcal{F}} x_{j t, 2}$ & -.466 & \multicolumn{4}{|c}{} \\
\hline \hline
\end{tabular}

We compute the correlations of the instruments with price over the entire sample, which covers March 1996 to November 2000. Recall that the counterfactual prices, $\widetilde{p}_{j t, m k}, \widetilde{p}_{j t, d}$ and $\widetilde{p}_{j t, \tau^{a}}$ are nonzero only for a few dates. This is driving the low reported correlation of these instruments with price. We only use the observable taste characteristics richness $\left(x_{j t, 2}\right)$, sweetness $\left(x_{j t, 3}\right)$, bitterness $\left(x_{j t, 4}\right)$, and alcoholic content $\left(x_{j t, 5}\right)$ to compute the instruments. To be clear, $z_{j t, 4}$ is the sum of all richness scores within firm $\mathcal{F}$ minus the richness score for variety $j . z_{j t, 8}$ sum all richness scores of products not sold by firm $\mathcal{F}$. 
Table 5: Explaining Observed Prices with the Instruments

\begin{tabular}{|l|r|r|r|r|}
\hline \hline & \multicolumn{2}{|c|}{$(\mathrm{I})$} & \multicolumn{2}{|c|}{ (II) } \\
Instrument & Coef. & t-Stat. & Coef. & t-Stat. \\
\hline \hline$\widetilde{p}_{t, m k}$ & .021 & 1.709 & -.007 & -.791 \\
\hline$\widetilde{p}_{t, d}$ & .035 & 2.134 & .047 & 4.185 \\
\hline$\widetilde{p}_{t, \tau^{a}}$ & -.026 & -3.342 & -.047 & -8.487 \\
\hline$z_{t, 4}$ & .236 & 8.210 & .112 & 4.765 \\
\hline$z_{t, 5}$ & -.074 & -3.257 & -.087 & -4.515 \\
\hline$z_{t, 6}$ & -.128 & -7.482 & -.138 & -10.021 \\
\hline$z_{t, 7}$ & -.089 & -4.444 & .055 & 2.804 \\
\hline$z_{t, 8}$ & .101 & 3.873 & .047 & 2.102 \\
\hline$z_{t, 9}$ & -.065 & -3.124 & -.076 & -4.101 \\
\hline$z_{t, 10}$ & -.062 & -4.562 & -.112 & -9.277 \\
\hline$z_{t, 11}$ & -.017 & -1.049 & .101 & 5.537 \\
\hline$z_{t, 12}$ & -3.905 & -6.279 & -2.453 & -1.700 \\
\hline$z_{t, 13}$ & -3.520 & -6.422 & 3.404 & 4.707 \\
\hline$z_{t, 14}$ & 2.883 & 10.382 & -.516 & -.774 \\
\hline$z_{t, 15}$ & 7.481 & 6.950 & -4.096 & -2.111 \\
\hline Trend & -.241 & -17.332 & .317 & 7.381 \\
\hline Constant & 22.376 & 3.273 & .037 & .759 \\
\hline Richness & - & - & -.116 & -3.499 \\
\hline Sweetness & - & - & 2.906 & 44.313 \\
\hline Bitterness & - & - & -.067 & -.945 \\
\hline Alcohol as \% of Vol. & - & - & 5.124 & 45.192 \\
\hline Advertising & - & - & 2.258 & 16.728 \\
\hline Foreign & - & - & 3.989 & 31.77 \\
\hline Bottle (50 cl) & - & - & 13.844 & 66.344 \\
\hline Bottle (33 cl) & - & - & 9.575 & 3.244 \\
\hline Can (33 cl) & - & - & -3.334 & -1.095 \\
\hline Ale & - & - & 4.722 & .758 \\
\hline Dark Lager & - & - & -9.094 & -2.825 \\
\hline Stout & - & - & -.098 & -7.327 \\
\hline Weissbeer & - & - & 53.312 & 7.433 \\
\hline \hline$R^{2}$ & 303.88 & & .71 & \\
F-Stat. & - & & 711.67 & \\
\hline \hline$(1)$ s & - & & & \\
\hline
\end{tabular}

(I) uses only the excluded instruments to explain observed prices, while (II) also uses the included instruments. (II) is therefore the first-stage regression of the instruments on the endogenous regressor. 
Table 6: Estimation Results

\begin{tabular}{|c|c|c|c|c|}
\hline \multirow[t]{2}{*}{ Regressor } & \multirow[t]{2}{*}{ Logit } & \multirow[t]{2}{*}{ Instrumented Logit } & \multicolumn{2}{|c|}{ BLP Model } \\
\hline & & & mean & std. dev., $\sigma_{k}$ \\
\hline Price per Liter & $\begin{array}{l}.064 \\
(.005)\end{array}$ & $\begin{array}{l}-.147 \\
(.016)\end{array}$ & $\begin{array}{c}\mathbf{- . 1 9 7 8} \\
(.027)\end{array}$ & $\begin{array}{l}\mathbf{. 0 6 4 2} \\
(.012)\end{array}$ \\
\hline Richness & $\begin{array}{l}\mathbf{. 0 9 9} \\
(.016)\end{array}$ & $\begin{array}{l}\mathbf{. 1 2 1} \\
(.017)\end{array}$ & $\begin{array}{c}\mathbf{. 1 0 8 6} \\
(.0438)\end{array}$ & - \\
\hline Sweetness & $\begin{array}{l}-.074 \\
(.019)\end{array}$ & $\begin{array}{c}-.059 \\
(.02)\end{array}$ & $\begin{array}{c}\mathbf{- 1 . 7 7 4} \\
(.279)\end{array}$ & $\begin{array}{l}\mathbf{1 . 8 0 7} \\
(.254)\end{array}$ \\
\hline Bitterness & $\begin{array}{l}-.14 \\
(.014)\end{array}$ & $\begin{array}{l}-.14 \\
(.014)\end{array}$ & $\begin{array}{c}\mathbf{- . 2 4 5 6} \\
(.043)\end{array}$ & - \\
\hline Alcohol as \% of Vol. & $\begin{array}{l}\mathbf{. 4 2 6} \\
(.031)\end{array}$ & $\begin{array}{l}\mathbf{. 6 4 7} \\
(.052)\end{array}$ & $\begin{array}{l}\mathbf{5 5 4 8} \\
(.102)\end{array}$ & $\begin{array}{l}\mathbf{. 5 5 4 8} \\
(.080)\end{array}$ \\
\hline Advertising (mln SEK) & $\begin{array}{l}\mathbf{. 3 9 5} \\
(.031)\end{array}$ & $\begin{array}{l}\mathbf{3 7 8} \\
(.031)\end{array}$ & $\begin{array}{l}\mathbf{. 3 8 5 1} \\
.035)\end{array}$ & - \\
\hline Foreign & $\begin{array}{l}. \mathbf{2 3 9} \\
(.056)\end{array}$ & $\begin{array}{l}\mathbf{. 6 8 3} \\
(.101)\end{array}$ & $\begin{array}{l}.7262 \\
(.195)\end{array}$ & - \\
\hline Bottle $(50 \mathrm{cl})$ & $\begin{array}{c}\mathbf{- 1 . 3 7 3} \\
(.06)\end{array}$ & $\begin{array}{l}\mathbf{- 1 . 1 4} \\
(.075)\end{array}$ & $\begin{array}{c}\mathbf{- . 9 4 1 8} \\
(.166)\end{array}$ & - \\
\hline Bottle $(33 \mathrm{cl})$ & $\begin{array}{c}-.836 \\
(.059)\end{array}$ & $\begin{array}{l}-.494 \\
(.088)\end{array}$ & $\begin{array}{c}-.5678 \\
(.103)\end{array}$ & - \\
\hline Can $(33 \mathrm{cl})$ & $\begin{array}{c}\mathbf{- 1 . 1 0 9} \\
(.114)\end{array}$ & $\begin{array}{l}\mathbf{. 0 6 2} \\
(.249)\end{array}$ & $\begin{array}{l}\mathbf{. 4 9 0 8} \\
(.310)\end{array}$ & - \\
\hline Ale & $\begin{array}{l}-.277 \\
(.092)\end{array}$ & $\begin{array}{l}.405 \\
(.159)\end{array}$ & $\begin{array}{c}\mathbf{. 8 6 3 8} \\
(.3912)\end{array}$ & - \\
\hline Dark Lager & $\begin{array}{l}-.635 \\
(.114)\end{array}$ & $\begin{array}{c}-.332 \\
(.13)\end{array}$ & $\begin{array}{c}\mathbf{- 1 . 3 9 5} \\
(.326)\end{array}$ & - \\
\hline Stout & $\begin{array}{l}-.075 \\
(.152)\end{array}$ & $\begin{array}{c}\mathbf{2 6} \\
(.167)\end{array}$ & $\begin{array}{c}-.2739 \\
(.416)\end{array}$ & - \\
\hline Weissbeer & $\begin{array}{c}\mathbf{- 1 . 3 6 7} \\
(.162)\end{array}$ & $\begin{array}{c}\mathbf{- 1 . 1 0 2} \\
(.173)\end{array}$ & $\begin{array}{c}\mathbf{- 1 . 0 6 0} \\
(.321)\end{array}$ & - \\
\hline Constant & $\begin{array}{c}\mathbf{- 5 . 3 9 1} \\
(.166)\end{array}$ & $\begin{array}{c}\mathbf{- 4 . 1 4 6} \\
(.289)\end{array}$ & $\begin{array}{l}\mathbf{. 5 5 1 7} \\
(.759)\end{array}$ & $\begin{array}{c}\mathbf{- 2 . 5 4 6} \\
(.393)\end{array}$ \\
\hline Linear Trend & $\begin{array}{l}\mathbf{- 0 . 0 4} \\
(.003)\end{array}$ & $\begin{array}{c}\mathbf{- 0 . 0 5 9} \\
(.004)\end{array}$ & $\begin{array}{c}\mathbf{- 0 . 0 2 8 2} \\
(.007)\end{array}$ & - \\
\hline $\begin{array}{l}\bar{\eta}_{j j} \\
\bar{\eta}_{j k} \\
\% \text { of Obs. } \eta_{j j}>-1 \\
\text { Sargan } \sim \chi^{2}(14) \\
\text { J-Stat. } \sim \chi^{2}(10)\end{array}$ & $\begin{array}{l}-2.20 \\
.004 \\
0 \% \\
- \\
-\end{array}$ & $\begin{array}{c}-5.04 \\
.008 \\
0 \% \\
8.7 \\
-\end{array}$ & & $\begin{array}{c}-5.57 \\
.017 \\
0 \% \\
- \\
18.21\end{array}$ \\
\hline
\end{tabular}

Based on 8,416 observations. The sample covers the period March 1996 to November 2000. The Swedish competition authority officialy cleared the merger between Carlsberg and Pripps in December 2000. The BLP model is estimated by efficient GMM and the standard errors are clustered at the firm-level. 
Figure 3: Distributions of the Random Coefficients
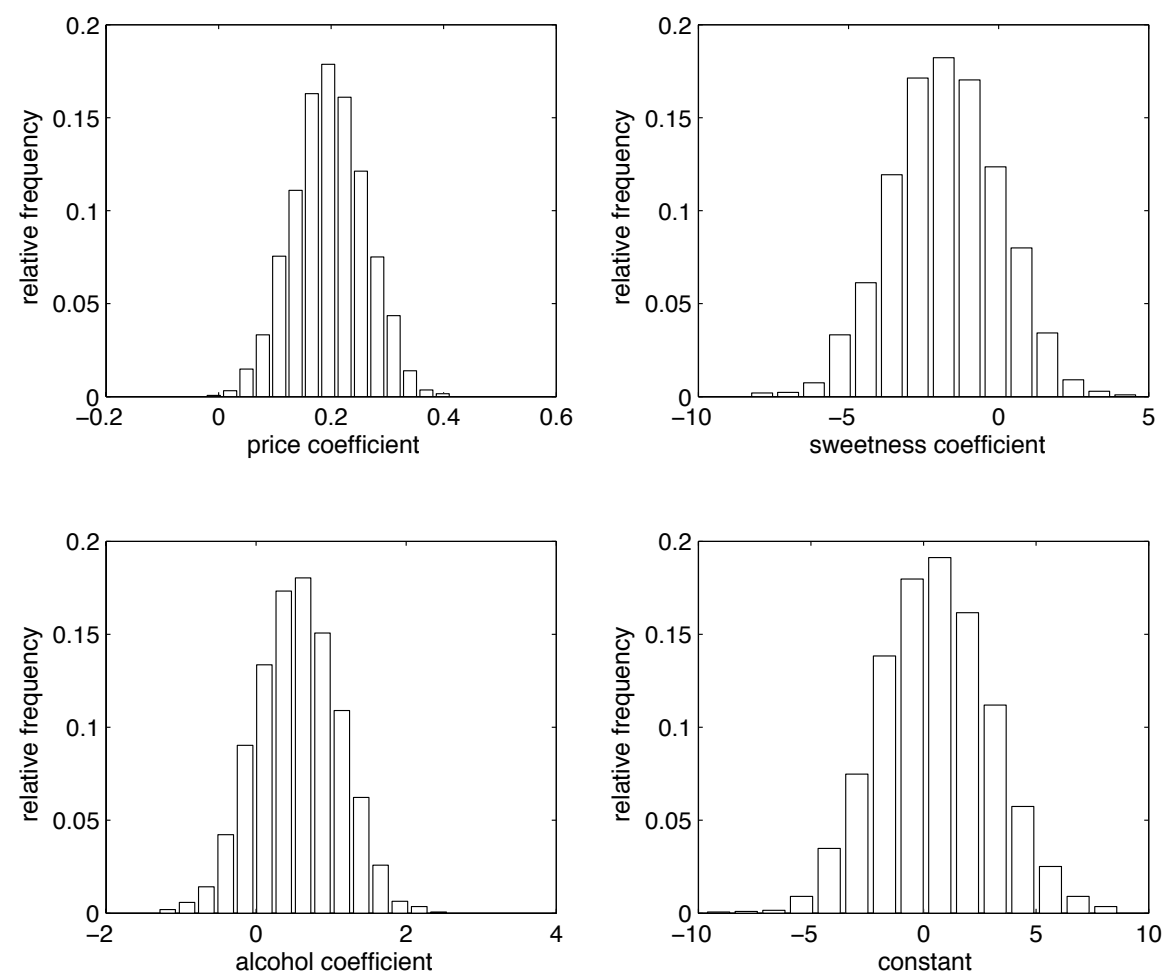

The distributions are based on $I=100$ simulated consumers that are resampled at each date. The draws are independent between product characteristics and consumers.

Table 7: Estimated Producer Markups (in \%)

\begin{tabular}{|l|c|c|}
\hline \hline & Instrumented Logit & BLP Model \\
\hline 1st percentile & 16.04 & 18.67 \\
\hline 5th percentile & 21.24 & 22.91 \\
\hline 25th percentile & 30.87 & 30.68 \\
\hline median & $\mathbf{4 2 . 9 9}$ & $\mathbf{3 9 . 0 2}$ \\
\hline mean & $\mathbf{4 2 . 9 0}$ & $\mathbf{3 9 . 6 3}$ \\
\hline 75th percentile & 53.5 & 47.31 \\
\hline 95th percentile & 66.54 & 59.80 \\
\hline 99th percentile & 84.2 & 71.55 \\
\hline \# obs. with markups $>1$ & 30 & 13 \\
\hline \hline
\end{tabular}

The table presents producer markups at the producer/wholesale level, $\left(p_{t}^{w}-m c_{t}^{w}\right) / p_{t}^{w}$, implied by the BLP model's demand estimates. The reported markups are pooled for all periods in our sample covering the period from March 1996 to November 2000. We use perfect knowledge of the retail monopoly's pricing rule, (9), to back out marginal costs at the wholesale level. 


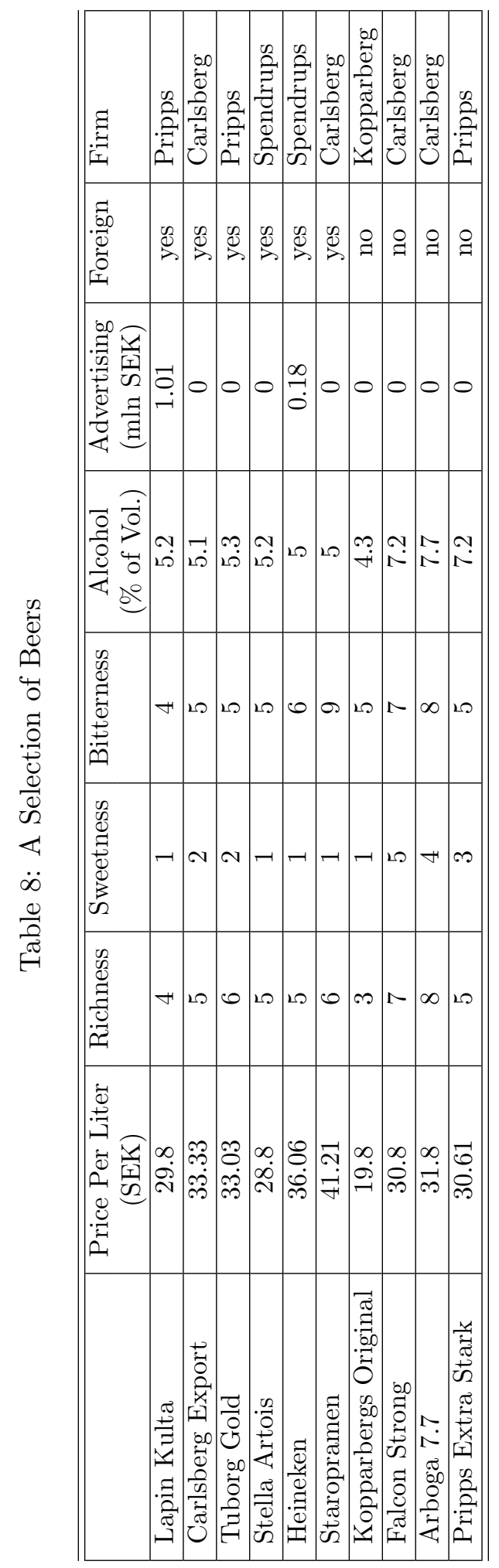




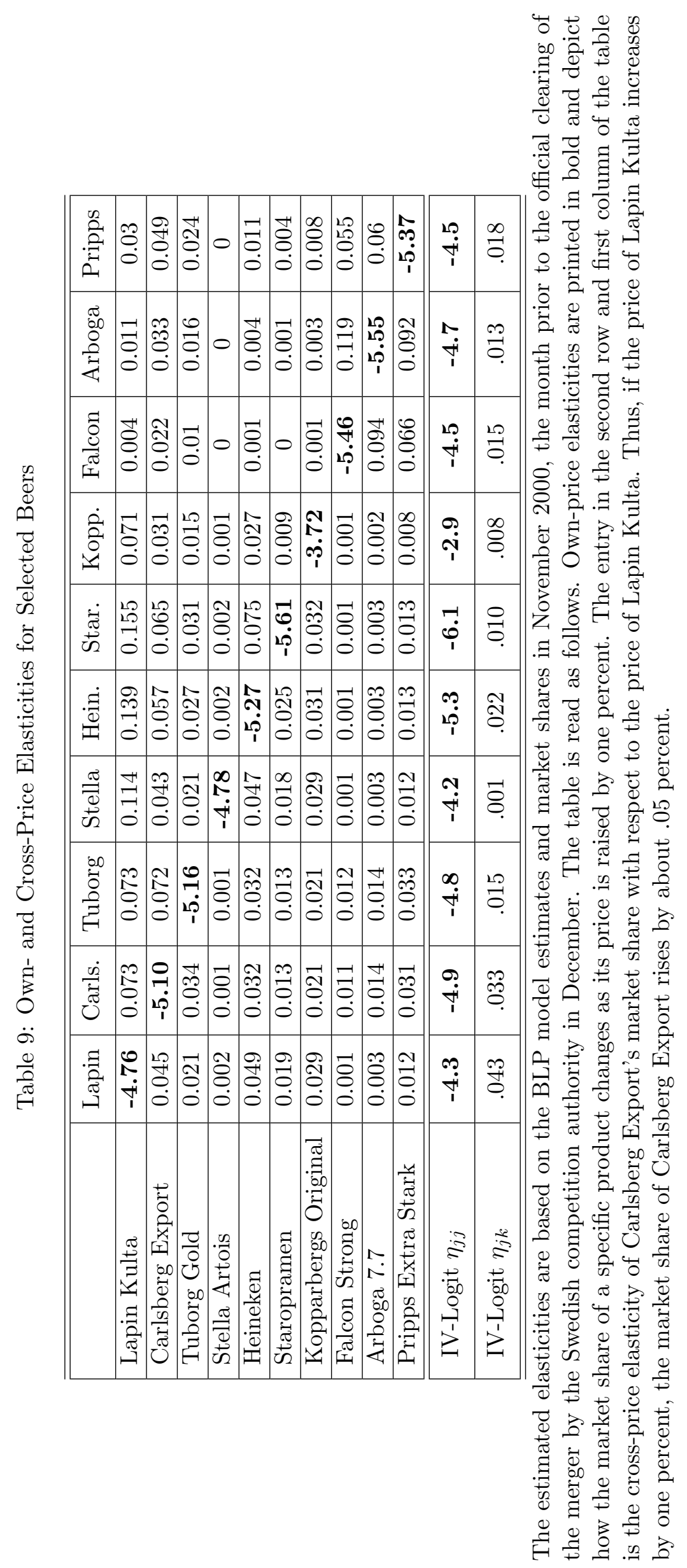


Table 10: Firms Directly Involved in the Merger, November 2000

\begin{tabular}{l|c|c|c|c}
\hline \hline & Carlsberg & Pripps & Galatea & Divestitures \\
\hline \# products & 46 & 27 & 16 & 19 \\
\hline $\begin{array}{l}\text { \# of products divested } \\
\text { post-merger }\end{array}$ & 16 & 3 & - & 19 \\
\hline$\sum_{j \in \mathcal{F}} s_{j, \text { Nov }}$ & .170 & .083 & .002 & .032 \\
\hline$\sum_{j \in \mathcal{F}}$ liter & & & & .061 \\
\hline \hline
\end{tabular}

November 2000 is the month prior to the official clearing of the merger between Carlsberg and Pripps by the Swedish competition authority in December. $\mathcal{F}$ denotes the set of products owned by a firm. $s_{j, N o v}$ is the market share of the particular beer $j$ in November, where we use the economic definition of market share. Thus, $s_{j, N o v}$ is the share of the relevant or potential market that beer $j$ captures, not its share of the total number of liters of beer sold in November, 2000 . The latter is reported by liter $_{j, N o v}$. 
Table 11: Counterfactual Merger Simulation

Average Retail Price Changes Post-Merger (in \%)

\begin{tabular}{l|c|c}
\hline \hline & (I) No Divestitures Imposed & (II)Divestitures Imposed \\
\hline Carlsberg & $\mathbf{4 . 4 2}$ & $\mathbf{- 3 . 1 7}$ \\
& {$[3.46,6.17]$} & {$[-4.16,-2.48]$} \\
\hline Pripps & $\mathbf{9 . 1 3}$ & $\mathbf{- . 3 8}$ \\
& {$[7.14,11.91]$} & {$[-.55, .4]$} \\
\hline Divestitures & $\mathbf{4 . 6 1}$ & $\mathbf{- 5 . 3 1}$ \\
& {$[3.78,5.5]$} & {$[-6.51,-4.25]$} \\
\hline Galatea & $\mathbf{- . 1 9}$ & $\mathbf{1 . 5 1}$ \\
& {$[-.4,-.08]$} & {$[1.17,1.96]$} \\
\hline All & $\mathbf{1 . 7 7}$ & $\mathbf{- . 5 1}$ \\
& {$[1.42,2.27]$} & {$[-.61,-.42]$} \\
\hline \hline
\end{tabular}

Change in Consumer Surplus (SEK, monthly)

\begin{tabular}{l|c|c}
\hline \hline & (I) No Divestitures Imposed & (II) Divestitures Imposed \\
\hline average, per & $\mathbf{- . 3 8}$ & $\mathbf{. 1 2}$ \\
individual & {$[-.46,-.31]$} & {$[.10, .15]$} \\
purchase & & $\mathbf{1 . 1 4}$ \\
\hline average, total & $\mathbf{- 3 . 6 3}$ & {$[.92,1.37]$} \\
market & {$[-4.38,-2.97]$} & \\
(mln SEK) & & \\
\hline \hline
\end{tabular}

Carlsberg and Pripps denote the actual holdings of products under the two merger scenarios. Thus, for case (I) the divestitures are included in the holdings of the two merging parties. This is naturally not the case for the column labelled (II). There, the numbers refer to the products that each firm is allowed to keep following the merger. The identity of the divestitures and Galatea always remains the same. Thus, in column (II), the divestitures are not included when computing Galatea's average price change. We compute the results in this way, to clearly state the pricing behavior of the divestitures for each of the merger cases. The numbers in square brackets are 95 percent confidence intervals for the reported means, which are based on 2,000 bootstraps using the asymptotic covariance matrix of the estimated (random) coefficients. When we compute the change in consumer surplus at the total market level, we use total liters of beer sold in November 2000 and not our definition of the total market (the sum of liters of beer and wine sold). 
Table 12: Counterfactual Merger Simulation - Spendrups Controls the Divestitures Post-Merger

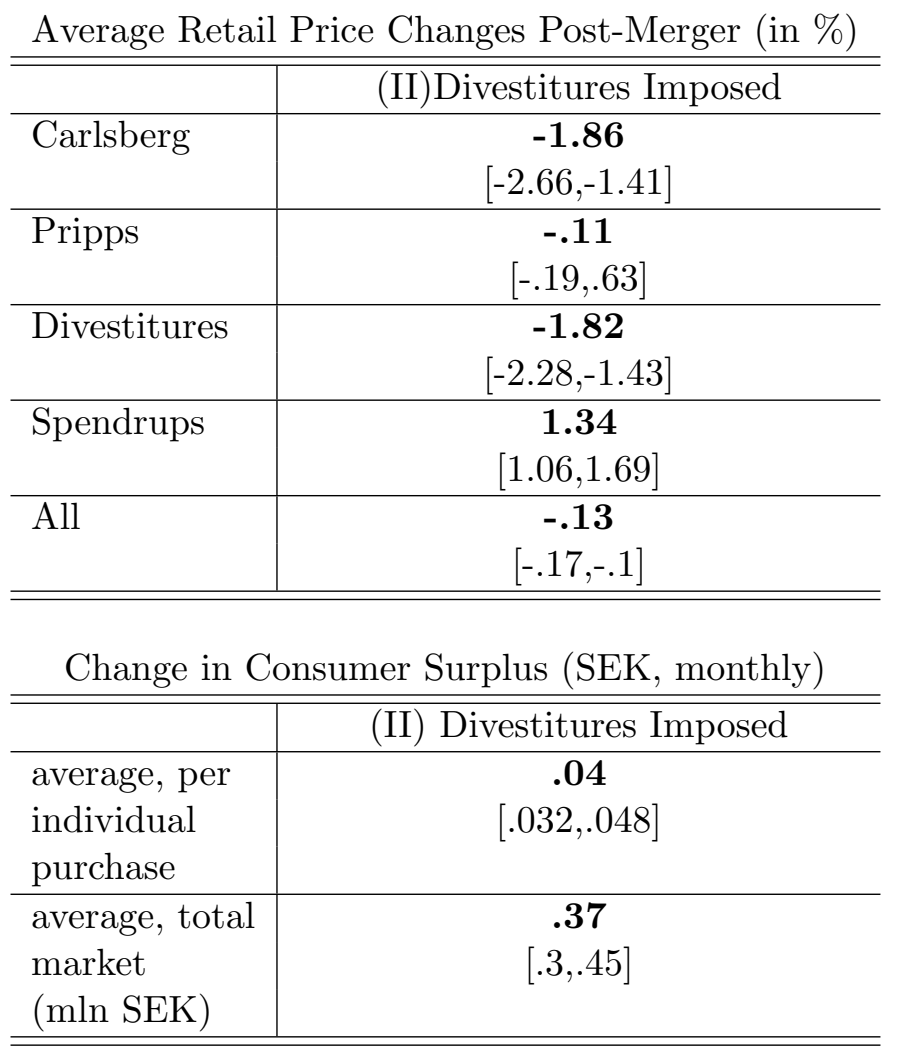

The numbers in square brackets are 95 percent confidence intervals for the reported means, which are based on 2,000 bootstraps using the asymptotic covariance matrix of the estimated (random) coefficients. These draws are identical to those used in the previous merger simulations. The results of the simulation without any divestitures are therefore identical to those reported in Table 12 and are therefore not reported here. The reported price effect for Spendrups only takes into account the products that Spendrups controlled pre-merger, so that we can clearly differentiate between the pricing behavior of the divested beers and those that belonged to Spendrups before the merger. When we compute the change in consumer surplus at the total market level, we use total liters of beer sold in November 2000 and not our definition of the total market (the sum of liters of beer and wine sold). 